\title{
Detection of Root-Knot Nematode Meloidogyne luci Infestation of Potato Tubers Using Hyperspectral Remote Sensing and Real-Time PCR Molecular Methods
}

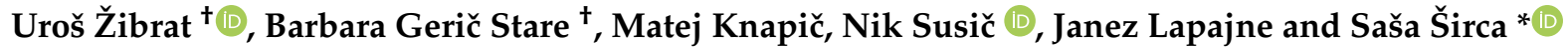 \\ Plant Protection Department, Agricultural Institute of Slovenia, Hacquetova ulica 17, SI-1000 Ljubljana, Slovenia; \\ uros.zibrat@kis.si (U.Ž.); barbara.geric@kis.si (B.G.S.); matej.knapic@kis.si (M.K.); nik.susic@kis.si (N.S.); \\ janez.lapajne@kis.si (J.L.) \\ * Correspondence: sasa.sirca@kis.si; Tel.: +386-1-280-5176 \\ + U.Ž. and B.G.S. contributed equally to this work as first authors.
}

check for

updates

Citation: Žibrat, U.; Gerič Stare, B.; Knapič, M.; Susič, N.; Lapajne, J.; Širca, S. Detection of Root-Knot

Nematode Meloidogyne luci

Infestation of Potato Tubers Using Hyperspectral Remote Sensing and Real-Time PCR Molecular Methods. Remote Sens. 2021, 13, 1996. https:// doi.org/10.3390/rs13101996

Academic Editor: Monica Pineda

Received: 21 April 2021

Accepted: 18 May 2021

Published: 20 May 2021

Publisher's Note: MDPI stays neutral with regard to jurisdictional claims in published maps and institutional affiliations.

Copyright: (C) 2021 by the authors. Licensee MDPI, Basel, Switzerland. This article is an open access article distributed under the terms and conditions of the Creative Commons Attribution (CC BY) license (https:// creativecommons.org/licenses/by/ $4.0 /)$.

\begin{abstract}
Root-knot nematodes (Meloidogyne spp.) are considered the most aggressive, damaging, and economically important group of plant-parasitic nematodes and represent a significant limiting factor for potato (Solanum tuberosum) production and tuber quality. Meloidogyne luci has previously been shown to be a potato pest having significant reproductive potential on the potato. In this study we showed that $M$. luci may develop a latent infestation without visible symptoms on the tubers. This latent infestation may pose a high risk for uncontrolled spread of the pest, especially via seed potato. We developed efficient detection methods to prevent uncontrolled spread of M. luci via infested potato tubers. Using hyperspectral imaging and a molecular approach to detection of nematode DNA with real-time PCR, it was possible to detect $M$. luci in both heavily infested potato tubers and tubers without visible symptoms. Detection of infested tubers with hyperspectral imaging achieved a 100\% success rate, regardless of tuber preparation. The real-time PCR approach detected M. luci with high sensitivity.
\end{abstract}

Keywords: potato infestation; latent tuber infestation; hyperspectral imaging; molecular detection; plant parasitic nematodes; Meloidogyne luci

\section{Introduction}

Plant-parasitic nematodes are tiny animals, obligate biotrophic parasites that obtain their nutrients from plant cells. The infestation symptoms are often non-specific, but some nematode genera, such as root-knot nematodes (RKN) Meloidogyne spp., develop typical deformations on roots and other underground plant organs such as potato tubers [1]. Several RKN species are capable of infesting the potato, Solanum tuberosum, where they cause the formation of root galls, surface galls on potato tubers and necrotic spots below the potato tuber skin. Two RKN species are listed on the quarantine list of the European Plant Protection Organization (EPPO), M. chitwoodi and M. fallax, and they are considered the most important plant parasitic nematode pests of the potato. They can cause total yield losses due to quality defects and quarantine issues [1] but potato production can also be threatened by other RKN species such as M. luci [2]. The pathogenicity of M. luci on the potato was studied in 16 commercial cultivars and all the cultivars were susceptible to $M$. luci, with relatively high pest reproduction factors, ranging from 12.5 to 72.9 [2]. Meloidogyne luci n. sp. described in 2014 by Carneiro et al. was isolated in different crops in Brazil, Chile, and Iran [3]. M. luci resembles M. ethiopica morphologically and biochemically, thus all populations of $M$. ethiopica reported in Europe and Turkey were reclassified and identified as M. luci [4]. Accordingly, M. luci has been detected several times in Europe in greenhouses on tomatoes in Slovenia [5,6] and Italy [7], in the field on maize in Greece [8], and in potato fields in mainland Portugal [2,9] and the Azores [10]. M. luci is a typical 
polyphagous pest that can parasitize both dicot and monocot herbaceous and woody plants, including many economically important crops. Although $M$. luci belongs to the tropical group of RKNs, its ability to survive winter in the field has been demonstrated in temperate and Mediterranean climates [11]. For all the above reasons, $M$. luci was recognised as an emerging problem and was included in the alert list of harmful organisms by the EPPO in 2017 [12]. M. ethiopica, a sister species of M. luci, which can also parasitize potatoes, is also classified as a harmful organism on the EPPO Alert List.

Traditionally, RKN species are identified by morphometric analysis and analysis of malate dehydrogenase (MDH) and esterase (EST) isozyme phenotypes [13]. Both methods require the isolation of mature females from the plant material, thus making them inefficient in terms of time and labour, and not suitable for a large number of samples. While biochemical analysis of isoenzymes is still considered as the most reliable method for the identification of tropical RKN species (i.e., clade I species in the genus Meloidogyne), identification based on morphometric measurements is often not possible for species in the tropical subgroup of RKN because of overlapping morphometric characteristics between species.

Hyperspectral imaging (HSI) is a non-destructive remote sensing method that can overcome the limitations of conventional potato tuber disease detection methods. Moreover, HSI is an imaging method and therefore generates large amounts of spectrally and spatially accurate data [14], which enables the assessment of large numbers of potato tubers in a comparatively short time. HSI acquires images containing spectral data from visible to near-infrared regions (400-1000 nm) and short-wavelength infrared regions (1000-2500 nm). Hyperspectral imaging can be used to resolve various plant stresses that alter the biochemical composition of plant tissue, enabling non-destructive phenotyping [15]. Invasion and infestation of plants by pests and pathogens trigger various defense mechanisms, such as induction of hypersensitive reactions, production of specific metabolites and proteins, and altered plant tissue structure [16], and can lead to different spectral signatures, depending on the biotic or abiotic stressor $[17,18]$. Detection of plant pests and pathogens can be achieved by measuring the reflectance, temperature, and fluorescence of plant tissues and their metabolites [19-21]. Tissue structure, pigment compositions, and biochemical properties vary depending on the stressor and can lead to different spectral signatures [18]. Remote sensing has been widely used for tuber quality assessment, e.g., detection of bruised tubers [22,23], color changes during processing [24], detection of defective tubers [25], textural attributes [26], starch and cellulose content [27], and various sugars [28]. Fewer studies have been published dealing with the detection in tubers of diseases such as hollow heart disease [29,30], common scab [31], and zebra chip disease [32]. Detection of nematode infestations using remote sensing methods has mainly focused on the detection of aboveground plant parts, and on detection of individual species (see [33] for a comprehensive review). A thorough search of the relevant literature did not reveal any publications dealing with the detection of nematode infestations in potato tubers using remote sensing, which underlines the importance of further research in this area.

In addition to morphometric and biochemical analysis, several molecular methods have been developed to identify different RKN species. For example, polymerase chain reaction (PCR) with species-specific primer pairs, polymerase chain reaction-restriction fragment length polymorphism (PCR-RFLP), quantitative polymerase chain reaction (qPCR), and loop-mediated isothermal amplification (LAMP) have been developed since the 1990s. The advantage of molecular methods is that they can be used with any life stage of nematodes, including eggs, juveniles, and adults as DNA sources. However, there is no diagnostic molecular method developed specifically for M. luci. A promising approach for molecular identification of $M$. luci and other tropical RKN species was demonstrated by [34], using a DNA barcoding approach with six mtDNA genes, but the method has so far not been adopted in diagnostic laboratories. A species-specific SCAR marker was developed for M. ethiopica, a sister species of $M$. luci [35], but this diagnostic method was 
not shown to be reliable and reproducible [36,37]. In contrast, $M$. luci can be detected with a PCR method using a primer pair specific for the Meloidogyne ethiopica group (MEG), i.e., for the three closely related and similar species M. ethiopica, M. luci, and M. inornata. [37]. With this approach, M. luci can be detected, but not distinguished from M. ethiopica or M. inornata.

The main aim of the present study was to develop hyperspectral imaging and PCRbased methods for the detection of M. luci infested potato tubers. We hypothesized, that both remote sensing and molecular methods can be used to detect infested tubers, including latent infestations (i.e., without visible symptoms). Detection of infested tubers, with or without visible (i.e., latent infestation) symptoms, using hyperspectral imaging partial least squares support vector machines (PLS-SVM) achieved a 100\% success rate, regardless of tuber preparation. Similarly, using the molecular approach it was possible to detect $M$. luci both in infested potato tubers with visible symptoms and in tubers without visible symptoms. Furthermore, M. luci was consistently detected in samples where only one peel of a symptomatic tuber was added to a sample of 100 peels in total, and when only three isolated females were added to a sample of uninfested potatoes, showing a low detection limit for the protocol. The study demonstrated for the first time the usefulness of hyperspectral remote sensing technology for the efficient detection of nematode-infested tubers and enabled the identification of latently infested tubers.

\section{Materials and Methods}

\subsection{Microplot Potato Cultivation}

The experiment on potato infestation with $M$. luci was established from June to September 2020 in a field-analogous microplot at the Agricultural Institute of Slovenia (GPS coordinates: 46.061402, 14.519247). The experiment was conducted in microplots with a concrete barrier ( $1 \mathrm{~m}^{2}$ square), which allowed the enclosed (quarantine) study of the soil pest under field-like conditions. The original microplot soil was of sandy loam type and was supplemented with peat substrate and inoculated with M. luci at the beginning of the experiment, as previously described in [18]. Briefly, tomato roots infested with $M$. luci (with egg-masses visible on the root surface) were cut into small pieces and carefully mixed. A subset of infested roots was then weighed and nematode eggs were collected in suspension according to [38]. Eggs were counted under a stereomicroscope Nikon SMZ800 (Nikon, Tokyo, Japan) to determine the number of nematode eggs per root weight. Infested roots were incorporated into the soil to a final concentration of $250 \times 10^{3} \mathrm{eggs} / \mathrm{plant}$. The identity of M. luci was confirmed with isoenzyme analysis, as described previously [4]. Prior to the experiment, the available phosphorous $\left(\mathrm{P}_{2} \mathrm{O}_{5}\right)$ and potassium $\left(\mathrm{K}_{2} \mathrm{O}\right)$ in the microplot soil were determined as $1 \mathrm{~g} / \mathrm{kg}$ and $0.2 \mathrm{~g} / \mathrm{kg}$, respectively, in all microplots. No additional fertilization was required. Two treatments were evaluated in the microplot experiment: (1) RKN treatment: potatoes infested with M. luci population SI-Smartno from the nematode collection at the Agricultural Institute of Slovenia; and (2) NC treatment: control microplot, where the plants were not infested. Four potato plants of Solanum tuberosum cv. Desiree were grown per microplot and each treatment was laid out in two microplots. Preventive control of late blight (Phytophthora infestans) on potatoes was carried out with the fungicide Acrobat ${ }^{\circledR} \mathrm{MZ}$ (Dimethomorph + Mancozeb, BASF), applied twice according to the manufacturer's instructions on the 27th and 52nd day after planting. Plants were sprayed evenly in both treatments. The environmental conditions from June to September 2020 were as follows: mean monthly temperature $20.4{ }^{\circ} \mathrm{C}$ (range from 17.6 to $22.5^{\circ} \mathrm{C}$ ), mean monthly precipitation $134 \mathrm{~mm}$ (range from 88.2 to $164 \mathrm{~mm}$ ), and mean monthly solar radiation $205.6 \mathrm{~kW} / \mathrm{m}^{2}$ (range from 154.7 to $262.9 \mathrm{~kW} / \mathrm{m}^{2}$ ). The microplot experiment was completed at the end of the growing season at 97 DAI. To assess nematode infestation, potato tubers were visually inspected. Similarly, four Solanum tuberosum cv. Desiree potato plants infested with $M$. fallax (a population from the nematode collection at the Agricultural Institute of Slovenia) were grown in one microplot. 


\subsection{Tuber Preparation}

Potato tubers were harvested at the end of the growing season on 23 September 2020 and stored in boxes in a dark storage room with ventilation and a temperature of $18 \pm 2{ }^{\circ} \mathrm{C}$ for the incubation period, until further processing.

Remote detection was performed 48 days after harvest. Potato tubers from the RKN treatment were divided into three groups: (1) low infestation-tubers with few (i.e., <10) visible symptoms (i.e., scars); (2) high infestation-tubers with multiple scars (i.e., >10); and (3) latent-tubers with no visible symptoms on the unpeeled tuber (Figure 1). Healthy, i.e., uninfested, tubers were used as the fourth group. In total, 32 tubers infested with $M$. luci were used: 11 low infestation tubers; 10 high infestation tubers; 11 latent infestation tubers; and 27 healthy tubers. A smaller subset of six tubers infested with $M$. fallax was used as a control to verify the identification of the pest species, using a remote sensing approach. Visibly decaying tubers were excluded from further analysis.
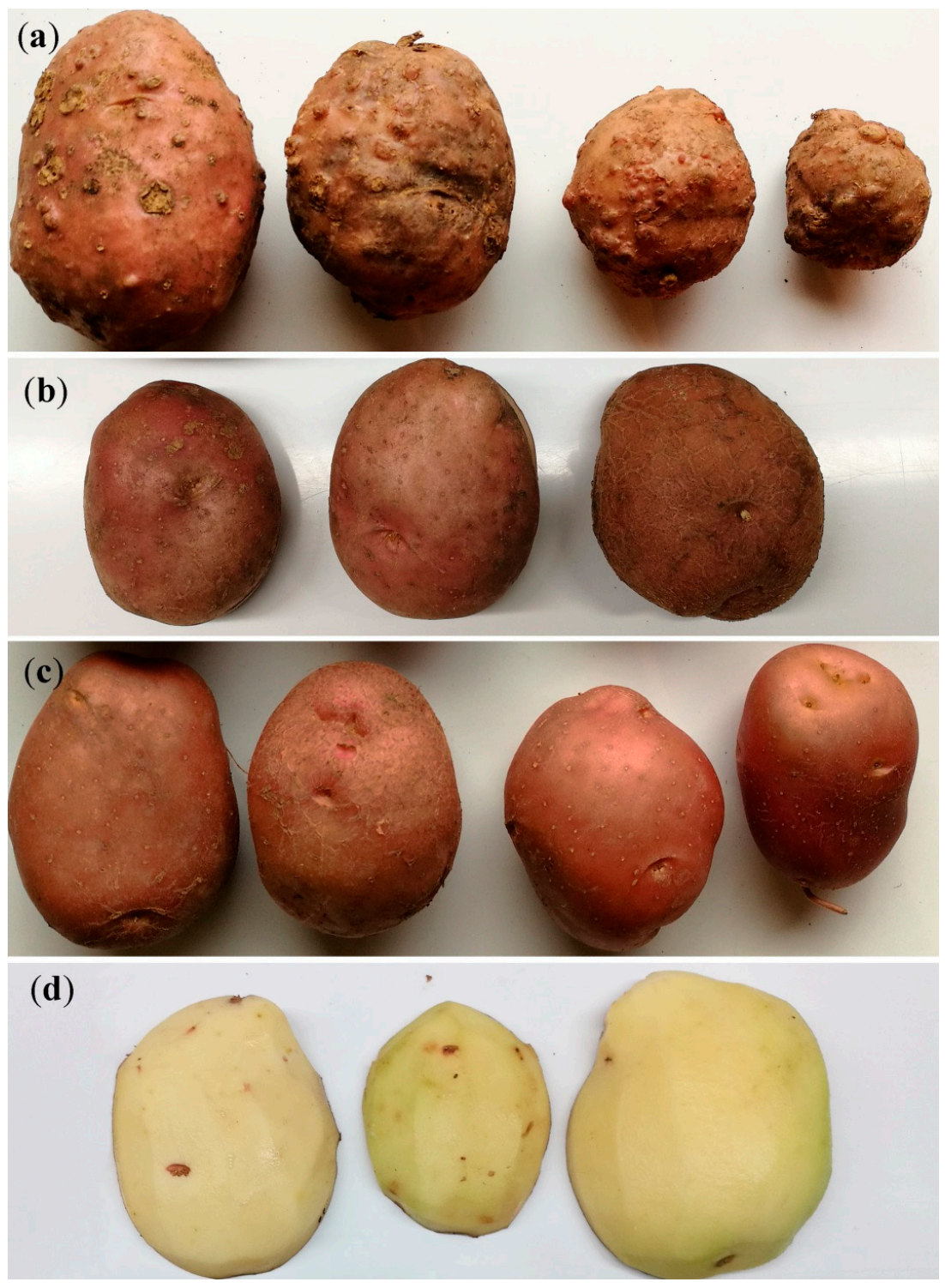

Figure 1. Cv. Desiree potato tubers after harvesting: (a) potato tubers from the RKN treatment with visible infestation symptoms - surface galls on potato tubers; (b) potato tubers from the RKN treatment without visual symptoms (i.e., latent infestation); (c) healthy, uninfested potato tubers from the control treatment; (d) peeled potato tubers from the RKN treatment without visual symptoms when unpeeled, with few visible necrotic spots below the potato tuber skin when peeled. 
For molecular detection, potato tubers infested with $M$. luci, i.e., from the RKN treatment, were divided into two groups: (1) tubers with visible symptoms; (2) tubers with no visible symptoms on the unpeeled tuber, i.e., latent infestation (Figure 1). Healthy, i.e., uninfested, tubers were used as control group. Individual females with egg mass attached were dissected from potato tuber tissue using a scalpel and nematological needle. Potato tubers were sampled 48 days after harvest for DNA isolation and stored in a refrigerator at $6 \pm 2{ }^{\circ} \mathrm{C}$ until further sampling 81 days after harvesting.

\subsection{Remote Detection}

\subsubsection{Image Acquisition}

Tubers from all the groups (healthy, low infestation, high infestation, and latent) were washed under running water and dried. Afterwards, the tubers were peeled twice at the same place, each peel with a thickness of $2 \mathrm{~mm}$. The secondary peel with a clean cortex layer was used for imaging. The tubers were then cut in half and all three sample types for each tuber (outer, peel, and inner) were placed in parallel on a laboratory rack set up for hyperspectral imaging (Figure 2). Up to nine tubers were scanned simultaneously. The moving platform, on which the tubers were placed for imaging was cleaned with $96 \%$ alcohol between scans, to avoid contamination. Reflectance spectra in the VNIR and SWIR regions were acquired using two Norsk Elektro Optikk AS (Oslo, Norway) pushbroom hyspex cameras, VNIR-1600 and SWIR-384 (combined range 400-2500 nm, bandwidth 3.6 and $5.4 \mathrm{~nm}$, respectively), mounted vertically above the samples at a distance of $1 \mathrm{~m}$. The samples were illuminated with two calibrated halogen lamps with homogeneous light intensity between 400 and $2500 \mathrm{~nm}$, placed above the samples next to the cameras. The lamps were switched on $15 \mathrm{~min}$ before image acquisition to stabilize the light source's temperature drift and establish spatial uniformity of illumination [39]. A calibrated diffuse grey reference plate with 50\% reflectance (SphereOptics, Herrsching, Germany) was included in each image and used to calculate reflectance. The signal-tonoise ratio was increased by scanning each line three times and calculating the average. Hyperspectral images were radiometrically calibrated to radiance units $\left(\mathrm{W} \mathrm{sr}^{-1} \mathrm{~m}^{-2}\right)$.

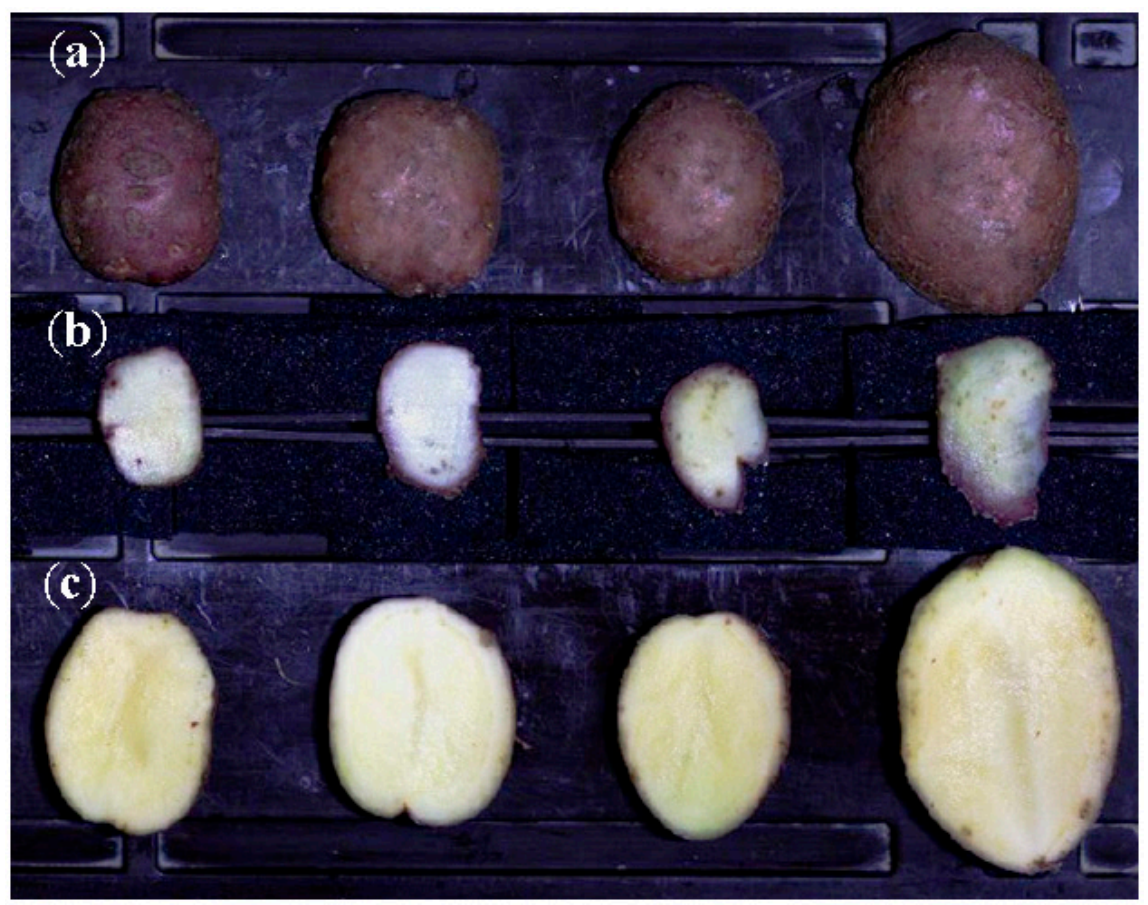

Figure 2. Potato tubers cv. Desiree highly infested with Meloidogyne luci prepared for remote sensing: (a) tubers cut in half, outer view; (b) secondary peels; (c) tubers cut in half, inner view. 


\subsubsection{Image Segmentation and Data Pre-Processing}

Image segmentation and pre-processing followed the guidelines described by [40]. The tuber and reference-plate area pixels were extracted using spectral information divergence [41] with four classes (reference plate, tuber-interior, tuber-exterior, and background). These segmentation masks also retained image pixel coordinates, which were then used to separate individual tubers and peels using K-means unsupervised classification. Spectral reflectance was then calculated for all tuber and peel pixels and area normalization was performed due to the variable geometry of the tubers. The reflectance values for each band of each image pixel (R) were calculated as follows:

$$
\mathrm{Ri}=\left(\mathrm{I}_{\mathrm{i}}-\mathrm{D}_{\mathrm{i}}\right) /\left(\left(\mathrm{W}_{\mathrm{i}}-\mathrm{D}_{\mathrm{i}}\right) / 0.95\right)
$$

where $I_{i}$ represents the reflected signal of the $i-t h$ band; $W_{i}$ is the reflected signal of the $i-t h$ band from the reference panel; and $D_{i}$ is the sensors' dark current of the $i$-th band.

Three simple filters were used to remove erroneous and misclassified pixels: (1) dead pixels, i.e., reflectance $<0.1 \%$ at each band; (2) specular reflectance, i.e., reflectance $>100 \%$ at each band; and (3) misclassifications were removed by calculating the median spectral signature and median absolute deviance (MAD), separately for each tuber and peel. Finally, data within $2 \mathrm{MAD}$ of the median were used to calculate the mean spectral signature of each tuber and peel. This process was repeated for both the VNIR and SWIR data sets. The mean spectral signatures from both systems were then combined to obtain full spectral signatures.

The mean reflectance data were smoothed using Savitzky-Golay second-order filters with a symmetric smoothing window of 15 points. Second order derivatives were then calculated for each spectral signature to remove scattering effects and highlight small spectral variations.

\subsubsection{Data Dimensionality Reduction and Feature Extraction}

Two methods were used for dimensionality reduction. Firstly, the data were visualized using t-Distributed stochastic neighbor embedding (t-SNE) [42]. The latter is a non-linear method that is particularly suitable for visualizing high-dimensional datasets. By minimizing the divergence between two distributions, t-SNE maps high-dimensional data to a two- or three-dimensional space and attempts to find patterns in the data, by identifying observed clusters. However, t-SNE is only a method for data exploration and visualization, since the input features are no longer identifiable and inferences about t-SNE outputs are not possible. Optimal settings (perplexity, initial dimensions, and maximum number of iterations) were determined on a trial-and-error basis.

Secondly, partial least squares discriminant analysis (PLS-DA) [43] was used as a method for dimensionality reduction and feature extraction of the data. Prior to analysis, variables were weighted using standard deviation weighting. PLS-DA models were developed separately for each of the three sample types (external, peel, and internal). The relevance of each wavelength to the classification was determined by calculating the importance of the variables in the projection (VIP) [44]. The developed models were validated using leave-one-out cross-validation.

\subsubsection{Supervised Classification}

Latent variables from the PLS-DA analysis were used as predictor variables in support vector machine (SVM) classification using the radial basis function kernel. The parameters for SVM classification (capacity factor and gamma) were determined by a grid search. The combinations that yielded the best accuracy (i.e., the highest number of correct classifications) were selected for model development. The classification models were validated using leave-one-out cross-validation. 
Image pre-processing and data extraction were performed in ENVI 5.1 (Harris Geospatial, Boulder, CO, USA). Data pre-processing, exploration, and analysis were performed in $\mathrm{R}$ [45], using the mixOmics [46], caret [47], and t-SNE [48] packages.

\subsection{Molecular Detection}

\subsubsection{Sampling}

For molecular detection, secondary (second layer) peels were taken from unwashed tubers by first peeling the periderm ( $2 \mathrm{~mm}$ thickness) and then cutting a secondary peel from the underlying clean cortex layer ( $2 \mathrm{~mm}$ thickness). For each sample, one hundred secondary peels from one hundred tubers (usually one peel per tuber) were pooled (weighing 89-109 g) and homogenized in $100 \mathrm{~mL}$ of distilled water using a Vorwerk mixer. Samples were homogenized for $4 \mathrm{~min}$, with the speed increased uniformly for the first $2 \mathrm{~min}$ and the maximum mixing speed applied for an additional $2 \mathrm{~min}$. The homogenized samples were poured from the mixing bowl into a $250 \mathrm{~mL}$ single use plastic container and allowed to settle for three minutes (Supplementary Figure S1). Then, $1 \mathrm{~mL}$ of the middle layer of the suspension (i.e., clear liquid layer) was transferred to a $1.5 \mathrm{~mL}$ microcentrifuge and allowed to settle for $10 \mathrm{~min}$. Two hundred microliters of the top layer of the supernatant was transferred to a new $1.5 \mathrm{~mL}$ microcentrifuge and used for DNA isolation directly or after storage at $-20^{\circ} \mathrm{C}$.

To avoid cross-contamination, the mixing bowl and lid were cleaned between samples with warm water and dishwashing detergent and DNA remover (Minerva Biotech $\mathrm{GmbH}$, Berlin, Germany).

Different types of potato tuber samples with a variable number of biological and technical replicates for DNA isolation and real-time PCR were processed as described in Table 1.

\subsubsection{DNA Isolation}

Two commercial DNA isolation kits were used for isolation of nematode DNA from potato tuber tissue: the Wizard Magnetic DNA Purifi-cation System for Food kit (Promega, Madison, WI, USA) and the Sbeadex maxi plant kit (LGC Genomics, Berlin, Germany), according to the manufacturers' instructions using the Kingfisher mL magnetic particle processor (Thermo Electron, Waltham, MA, USA) and protocols available in Supplementary material as Protocol S1 and Protocol S2. With the first commercial DNA isolation kit, DNA was eluted in $100 \mu \mathrm{L}$ of nuclease-free water, whereas with the other kit, DNA was eluted in $100 \mu \mathrm{L}$ of elution buffer.

Genomic DNA used in standard curve analysis was isolated from M. luci J2 larvae using a conventional protocol, as described previously [49].

\subsubsection{Real-Time PCR}

The relative amount of DNA isolated with the two different commercial kits was evaluated with real-time PCR using a eukaryotic $18 \mathrm{~S}$ rRNA endogenous control (Thermo Fischer Scientific, Waltham, MA, USA), according to the manufacturer's instructions.

M. luci infestation was detected with real-time PCR using primers Me309 (TAATTTGGG TGAATTT) and Me549 (AATCAAAATCTTCTCCT) specific for the Meloidogyne ethiopica group (MEG) [37]. The reaction was performed in a $25-\mu \mathrm{L}$ mix containing Power Sybr Green PCR Master Mix (Applied Biosystems, Thermo Fischer Scientific, Waltham, MA, USA), $1 \mu \mathrm{L}$ of each primer at a concentration of $10 \mu \mathrm{M}, 2.5-10.5 \mu \mathrm{L}$ of template DNA, and additional nuclease-free water if necessary to achieve the total reaction volume. Cycling conditions were as follows: initial denaturation for $10 \mathrm{~min}$ at $94{ }^{\circ} \mathrm{C}, 35$ cycles of denaturation for $15 \mathrm{~s}$ at $94{ }^{\circ} \mathrm{C}$, annealing for $30 \mathrm{~s}$ at $50^{\circ} \mathrm{C}$, and elongation for $1 \mathrm{~min}$ at $60^{\circ} \mathrm{C}$, followed by a final elongation for $5 \mathrm{~min}$ at $60^{\circ} \mathrm{C}$ and a melting curve. An ABI7500 Fast Cycler (Applied Biosystems) with 7500 software v2.0.6 (Life Technologies, Applied Biosystems) was used for DNA amplification. All $C_{T}$ values reported in Table 1 were determined with the same Ct threshold. 
The standard curve for real-time reaction with MEG specific primers was determined using genomic DNA isolated from M. luci J2 larvae. Fivefold dilutions of M. luci genomic DNA were prepared in nuclease-free water (from a concentration of $129.7 \mathrm{ng} / \mu \mathrm{L}$ to $66.4 \mathrm{fg} / \mu \mathrm{L}$ ) and used in triplicate in real-time PCR reactions with MEG primers.

Table 1. Types of potato tuber samples with the number of biological and technical replicates processed to detect Meloidogyne luci infestation on potato tubers. All threshold cycle $\left(\mathrm{C}_{\mathrm{T}}\right)$ values were obtained at the same $\mathrm{C}_{\mathrm{T}}$ threshold.

\begin{tabular}{|c|c|c|c|c|}
\hline Sample Type & $\begin{array}{l}\text { Biological } \\
\text { Replicates }\end{array}$ & $\begin{array}{l}\text { Technical Replicates } \\
\text { DNA Isolation }\end{array}$ & $\begin{array}{c}\text { Technical Replicates } \\
\text { Real-Time PCR }\end{array}$ & $\mathrm{C}_{\mathrm{T}}$ \\
\hline \multirow{3}{*}{$\begin{array}{l}50 \text { peels from the RKN treatment-tubers } \\
\text { with visible symptoms and } 50 \text { peels from the } \\
\text { uninfested (NC) treatment }\end{array}$} & 1 & 1 & 1 & 23.0 \\
\hline & 1 & $2^{a}$ & 1 & 26.1 \\
\hline & 1 & $3^{b}$ & 1 & 25.0 \\
\hline \multirow{6}{*}{$\begin{array}{l}100 \text { peels from the RKN treatment-tubers } \\
\text { without visible symptoms (latent infestation) }\end{array}$} & 1 & 1 & 1 & 24.5 \\
\hline & 1 & $2^{a}$ & 1 & 29.2 \\
\hline & 1 & $3^{b}$ & 1 & 26.7 \\
\hline & 2 & 1 & 1 & 25.4 \\
\hline & 2 & 2 & 1 & 22.5 \\
\hline & 2 & 3 & 1 & 24.0 \\
\hline \multirow{11}{*}{$\begin{array}{l}99 \text { peels from the uninfested }(\mathrm{NC}) \text { treatment } \\
\text { and one peel from the RKN treatment, one } \\
\text { tuber with visible symptoms }\end{array}$} & 1 & 1 & 1 & 28.6 \\
\hline & 1 & $2^{a}$ & 1 & 31.1 \\
\hline & 1 & $3^{b}$ & 1 & 30.9 \\
\hline & 2 & 1 & 1 & 28.4 \\
\hline & 2 & 1 & 2 & 32.4 \\
\hline & 2 & 1 & 3 & 32.5 \\
\hline & 2 & 2 & 1 & 31.0 \\
\hline & 2 & 3 & 1 & 28.1 \\
\hline & 3 & 1 & 1 & 28.6 \\
\hline & 3 & 2 & 1 & 28.3 \\
\hline & 3 & 3 & 1 & 28.5 \\
\hline \multirow{3}{*}{$\begin{array}{l}100 \text { peels from the uninfested (NC) treatment } \\
\text { with addition of three RKN females }\end{array}$} & 1 & 1 & 1 & 29.6 \\
\hline & 1 & $2^{a}$ & 1 & 32.0 \\
\hline & 1 & $3^{b}$ & 1 & 32.3 \\
\hline \multirow{6}{*}{$\begin{array}{l}100 \text { peels from the uninfested }(\mathrm{NC}) \text { treatment } \\
\text { with addition of one RKN female }\end{array}$} & 1 & 1 & 1 & und. \\
\hline & 1 & $2^{a}$ & 1 & 34.2 \\
\hline & 1 & $3^{b}$ & 1 & und. \\
\hline & 2 & 1 & 1 & und. \\
\hline & 2 & $2^{a}$ & 1 & und. \\
\hline & 2 & $3^{b}$ & 1 & und. \\
\hline \multirow{9}{*}{100 peels from the uninfested (NC) treatment } & 1 & 1 & 1 & und. \\
\hline & 1 & $2^{a}$ & 1 & und. \\
\hline & 1 & $3^{b}$ & 1 & und. \\
\hline & 2 & 1 & 1 & und. \\
\hline & 2 & 2 & 1 & und. \\
\hline & 2 & 3 & 1 & und. \\
\hline & 3 & 1 & 1 & und. \\
\hline & 3 & 2 & 1 & und. \\
\hline & 3 & 3 & 1 & und. \\
\hline
\end{tabular}

a Sample isolated with the Sbeadex maxi plant kit (LGC Genomics, Berlin, Germany) and $10.5 \mu \mathrm{L}$ template DNA used in a real-time PCR reaction. ${ }^{\mathrm{b}}$ Sample isolated with the Sbeadex maxi plant kit (LGC Genomics, Berlin, Germany) and $2.5 \mu \mathrm{L}$ template DNA used in a real-time PCR reaction. The rest of the samples were isolated with the Wizard Magnetic DNA Purification System for Food kit (Promega, Madison, WI, USA) and $10.5 \mu \mathrm{L}$ template DNA used in a real-time PCR reaction. Und.: undetected. RKN treatment: potatoes infested with $M$. luci population SI-Smartno from the nematode collection of the Agricultural Institute of Slovenia. NC treatment: control microplot where the potato was not infested. 


\section{Results}

\subsection{Symptoms of M. luci Infestation}

In the microplot cultivation setup, the eight potato plants infested with M. luci yielded 50 potato tubers with a diameter of over $2 \mathrm{~cm}$. At the end of the growing period, typical root galls were observed on the roots (Supplementary Figure S2). Approximately two thirds of the tubers developed characteristic visible symptoms of RKN infestation, i.e., surface galls on potato tubers looking like small pimple-like swellings on the tuber surface (Figure 1a). Approximately one third of the tubers displayed no visible symptoms on the surface (Figure 1b), but females were present below the potato tuber skin and revealed on the peeled tubers as necrotic spots (Figure 1d). Within these spots, adult females were seen, attached to an external egg mass with a gelatinous appearance. Tubers with no visible symptoms on the surface but with viable nematodes present below the skin surface were defined as latent infestation (Figure 1b).

Forty-eight days after harvesting and storage at $18 \pm 2{ }^{\circ} \mathrm{C}$, the potato tubers displayed slightly more severe infestation symptoms. Six tubers with no visible symptoms at harvest time developed visible symptoms after 48 -day storage at $18 \pm 2{ }^{\circ} \mathrm{C}$, which allowed further development of nematodes in the potato tubers.

\subsection{Remote Detection}

In addition to symptoms observed with the naked eye, symptoms of $M$. luci infestation were observed by analyzing hyperspectral images. Detection of infested tubers using hyperspectral imaging partial least squares support vector machines (PLS-SVM) achieved a success rate of $100 \%$, regardless of tuber preparation (Table 2). The same success rate was achieved in distinguishing latent infestations from healthy tubers. A similar success rate was achieved for identification of infestation severity, with one tuber misclassified in each tuber preparation group (Table 3). With image data from the tuber epidermis, one latent tuber was misclassified as low infestation, in peeled samples one healthy sample was misclassified as low infestation, and in images of the inside of tubers a low infestation tuber was misclassified as high infestation. The good separation between treatment groups was also evident in the t-SNE scatter plots (Figure 3). The greatest differences in the spectral signatures of the treatment groups were observed in tuber epidermis images, where healthy tubers had the highest reflectance in the 800-1000 nm range and the lowest from $1500 \mathrm{~nm}$ onwards (Figure 4). These differences were not so pronounced in peeled and halved tubers. Savitzky-Golay derivatives showed some common differences between healthy and infested tubers (Figure 5). For example, a peak at $671 \mathrm{~nm}$, where healthy tubers had the highest values and infested tubers (high infestation) had the lowest values, was observed in all three tuber image groups (external, internal, and peeled). At $1026 \mathrm{~nm}$, a dip with healthy tubers showing the lowest values was observed in internal and peeled data. Another characteristic pattern was observed in a series of two peaks with a dip between them, at wavelengths 1776, 1841, and 1890. In this series, healthy tubers were always on the outside, i.e., highest values in the peaks and lowest in the dip, and latent tubers were on the inside, i.e., lowest values in the peaks and highest in the dip. Interestingly, the images of the epidermis generally showed the same pattern, but the second peak shifted to $1917 \mathrm{~nm}$ and developed a shoulder at $1890 \mathrm{~nm}$ in infested tubers. In peeled samples, a similar pattern was observed at 981 and $1004 \mathrm{~nm}$, with a dip and a peak, respectively. In this case, infested tubers had a larger difference in values between the dip and peak, while healthy tubers had the smallest difference. These results were confirmed by the variable importance in projection analysis, which was used to determine which wavelengths were relevant for identifying infested tubers (Figure 6). The relevance of reflection at $970 \mathrm{~nm}$ was common to all cases. Other relevant wavelengths for the detection of infestation and its severity were the peak-dip-peak sequence between 1776 and $1890 \mathrm{~nm}$, and spectral ranges around $785,812,1146,1238,1352,1450,1635,1705,1765,2276$, and $2330 \mathrm{~nm}$. The pattern of relevant wavelengths was different in the tuber epidermis data, where wavelengths 1559, 1982, 2270, and 2385 were relevant. 
Table 2. Partial least squares discriminant analysis (PLS-DA) and partial least squares support vector machine (PLS-SVM) results for all experiments to detect Meloidogyne luci and M. fallax in potato tubers using hyperspectral imaging. LV: number of PLS latent variables; N: number of tubers; Var (\%): amount of variance explained by the selected LVs; RMSECV: root mean squared error of cross-validation; CL: 95\% confidence limits.

\begin{tabular}{|c|c|c|c|c|c|c|c|c|c|c|}
\hline \multirow[t]{2}{*}{ Group } & \multirow[t]{2}{*}{ Treatment } & \multirow[t]{2}{*}{$\mathbf{N}$} & \multicolumn{3}{|c|}{ PLS-DA } & \multicolumn{5}{|c|}{ PLS-SVM } \\
\hline & & & LV & $\operatorname{Var}(\%)$ & RMSECV & c & Gamma & Accuracy & CL & Kappa \\
\hline \multirow{3}{*}{$\underset{ت}{\tilde{\Xi}}$} & External & 59 & 10 & 75.4 & 0.71 & 0.77 & 0.1 & 0.983 & 0.909-0.999 & 0.975 \\
\hline & Internal & 59 & 10 & 81.9 & 0.75 & 0.527 & 0.046 & 0.983 & 0.909-0.999 & 0.975 \\
\hline & Peeled & 59 & 10 & 68.0 & 0.61 & 1 & 0.1 & 0.983 & 0.909-0.999 & 0.975 \\
\hline \multirow{2}{*}{ 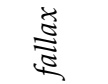 } & External & 65 & 5 & 80.5 & 0.8 & 1 & 0.032 & 1 & $0.945-1$ & 1 \\
\hline & Internal & 65 & 6 & 64.8 & 0.81 & 10 & 0.01 & 1 & 0.945-1 & 1 \\
\hline$\dot{\Sigma}$ & Peeled & 65 & 9 & 78.3 & 0.76 & 0.599 & 0.017 & 0.985 & $0.917-0.999$ & 0.973 \\
\hline
\end{tabular}

Table 3. Confusion matrices and partial least squares support vector machine (PLS-SVM) classification results for detection of Meloidogyne luci and M. fallax in potato tubers using hyperspectral imaging. Lt: latent infestation; Lo: Low infestation; Hi: High infestation; He: Healthy; Mf: M. fallax infestation; Ml: M. luci infestation; Ex: Exterior; In: Interior; Pe: Peel.

\begin{tabular}{|c|c|c|c|c|c|c|c|c|c|c|c|}
\hline \multirow[b]{2}{*}{ Group } & & \multirow[b]{2}{*}{$\mathbf{L t}$} & \multicolumn{3}{|c|}{ Predicted } & \multirow[b]{2}{*}{ Sensitivity } & \multirow[b]{2}{*}{ Specificity } & \multirow[b]{2}{*}{ Precision } & \multirow[b]{2}{*}{ Recall } & \multirow[b]{2}{*}{ F1 } & \multirow[b]{2}{*}{ Balanced Accuracy } \\
\hline & & & Lo & $\mathrm{Hi}$ & $\mathrm{He}$ & & & & & & \\
\hline \multirow{4}{*}{ Ex } & $\mathrm{Lt}$ & 10 & 1 & & & 1 & 0.98 & 0.91 & 1 & 0.952 & 0.99 \\
\hline & Lo & & 11 & & & 0.917 & 1 & 1 & 0.917 & 0.957 & 0.958 \\
\hline & $\mathrm{Hi}$ & & & 10 & & 1 & 1 & 1 & 1 & 1 & 1 \\
\hline & $\mathrm{He}$ & & & & 27 & 1 & 1 & 1 & 1 & 1 & 1 \\
\hline \multirow{4}{*}{ In } & $\mathrm{Lt}$ & 11 & & & & 1 & 1 & 1 & 1 & 1 & 1 \\
\hline & Lo & & 10 & 1 & & 1 & 0.98 & 0.909 & 1 & 0.952 & 0.99 \\
\hline & $\mathrm{Hi}$ & & & 10 & & 0.909 & 1 & 1 & 0.909 & 0.952 & 0.95 \\
\hline & $\mathrm{He}$ & & & & 27 & 1 & 1 & 1 & 1 & 1 & 1 \\
\hline \multirow{5}{*}{$\mathrm{Pe}$} & $\mathrm{Lt}$ & 11 & & & & 1 & 1 & 1 & 1 & 1 & 1 \\
\hline & Lo & & 11 & & & 0.917 & 1 & 1 & 0.917 & 0.957 & 0.958 \\
\hline & $\mathrm{Hi}$ & & 1 & 9 & & 1 & 0.98 & 0.9 & 1 & 0.947 & 0.99 \\
\hline & $\mathrm{He}$ & & & & 27 & 1 & 1 & 1 & 1 & 1 & 1 \\
\hline & & Mf & Ml & $\mathrm{He}$ & & Sensitivity & Specificity & Precision & Recall & F1 & Balanced Accuracy \\
\hline \multirow{3}{*}{ Ex } & Mf & 6 & & & & 1 & 1 & 1 & 1 & 1 & 1 \\
\hline & Ml & & 32 & & & 1 & 1 & 1 & 1 & 1 & 1 \\
\hline & $\mathrm{He}$ & & & 27 & & 1 & 1 & 1 & 1 & 1 & 1 \\
\hline \multirow{3}{*}{ In } & Mf & 6 & & & & 1 & 1 & 1 & 1 & 1 & 1 \\
\hline & $\mathrm{Ml}$ & & 32 & & & 1 & 1 & 1 & 1 & 1 & 1 \\
\hline & $\mathrm{He}$ & & & 27 & & 1 & 1 & 1 & 1 & 1 & 1 \\
\hline \multirow{3}{*}{$\mathrm{Pe}$} & Mf & 6 & & & & 1 & 1 & 1 & 1 & 1 & 1 \\
\hline & $\mathrm{Ml}$ & & 31 & 1 & & 1 & 0.971 & 0.969 & 1 & 0.984 & 0.985 \\
\hline & $\mathrm{He}$ & & & 27 & & 0.964 & 1 & 1 & 0.964 & 0.982 & 0.982 \\
\hline
\end{tabular}

Similar classification results were obtained in distinguishing between tubers infested with M. fallax and M. luci. Both the internal and external samples had a $100 \%$ success rate, while one tuber infested with $M$. luci was misclassified as healthy in the peeled images (Table 2). The separation between M. luci and M. fallax was further illustrated in t-SNE plots, although two groups of $M$. luci-infested tubers were found in the internal tuber data (Figure 7). In general, derivative spectra of $M$. fallax showed similar patterns to those of M. luci. For example, the same shift from 1890 to $1917 \mathrm{~nm}$ was observed in epidermis data, and healthy tubers had the highest values at a peak at $671 \mathrm{~nm}$. In both peeled and internal data, a dip was observed at $1026 \mathrm{~nm}$, with healthy tubers again having lower values. When distinguishing between the two nematode species, more distinct differences were observed in the VNIR region. For example, in external images, M. luci showed a 
peak-dip-peak series at 646,675 , and $704 \mathrm{~nm}$, where the curve of $M$. fallax was almost flat. At $741 \mathrm{~nm}$ M. fallax showed a peak, while M. luci showed a shoulder, and at $704 \mathrm{~nm}$, a dip was absent from the $M$. fallax data. Regardless of the visible differences in the derivative spectra, several additional relevant wavelengths were identified using VIP analysis. The most relevant wavelengths for peeled and internal samples remained in the VNIR range (e.g., 11 wavelengths were identified as relevant in the visible spectrum range), only four wavelengths above $1000 \mathrm{~nm}$ were identified as relevant for distinguishing between $M$. fallax and M. luci: 1091, 1145, 1346, and $1808 \mathrm{~nm}$. In external images, the SWIR range gained several additional relevant wavelengths, e.g., 2058, 2107, 2281, and $2400 \mathrm{~nm}$ (Figure 8).
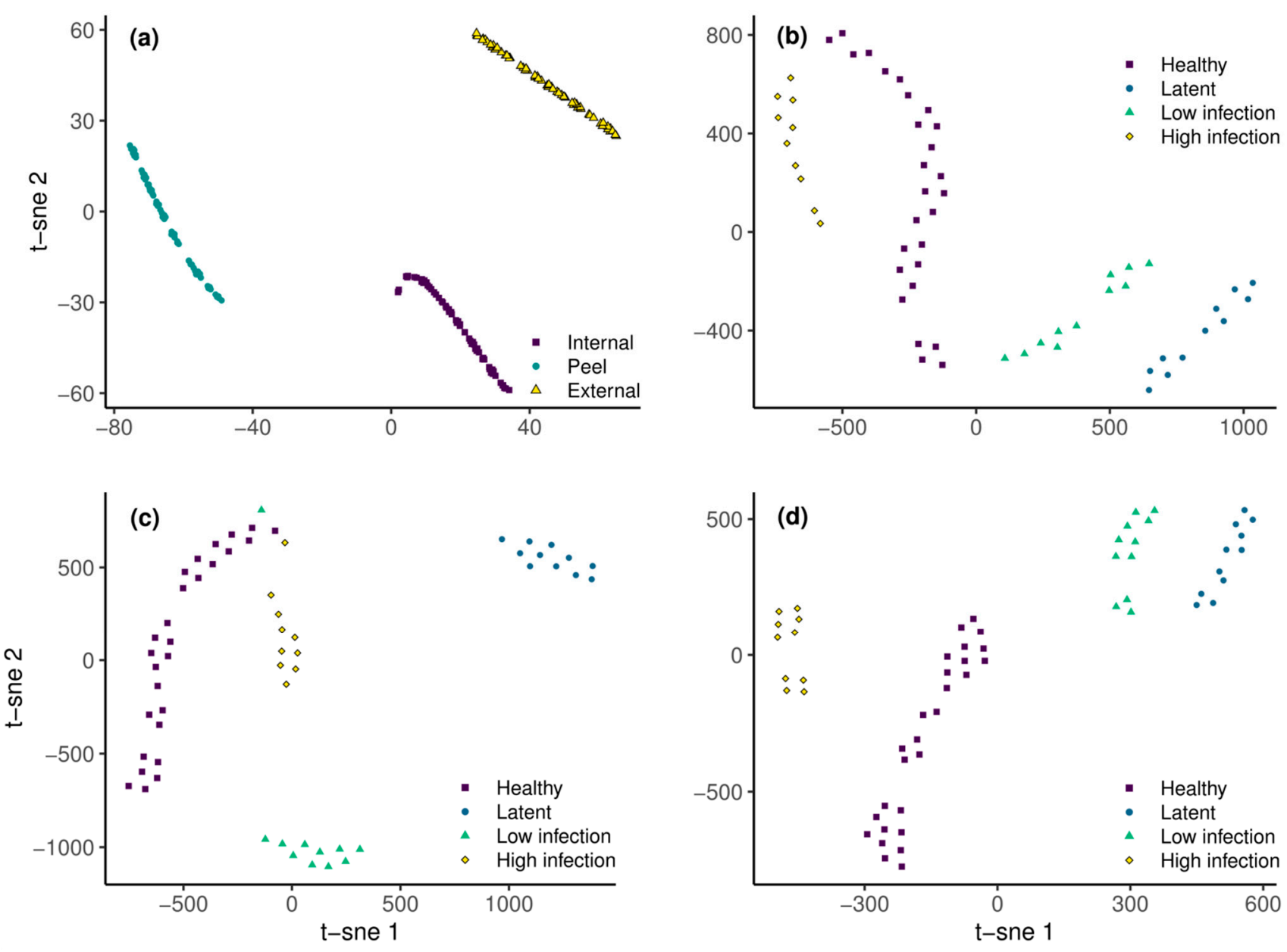

Figure 3. t-SNE scatter plots of spectral derivative data. (a) Tuber preparation groups; (b) internal data from halved tubers; (c) data from peels; (d) epidermis data.

\subsection{Molecular Detection}

DNA was successfully isolated using both commercial kits for DNA isolation. The $\mathrm{C}_{\mathrm{T}}$ values for the control real-time PCR reaction that amplifies eukaryotic $18 \mathrm{~S}$ rRNA were consistently lower (by 0.44 cycles on average) when Wizard Magnetic DNA Purification System for Food kit (Promega) was used for DNA isolation. Therefore, most of the results presented for the detection of $M$. luci refer to DNA isolated using this kit. 

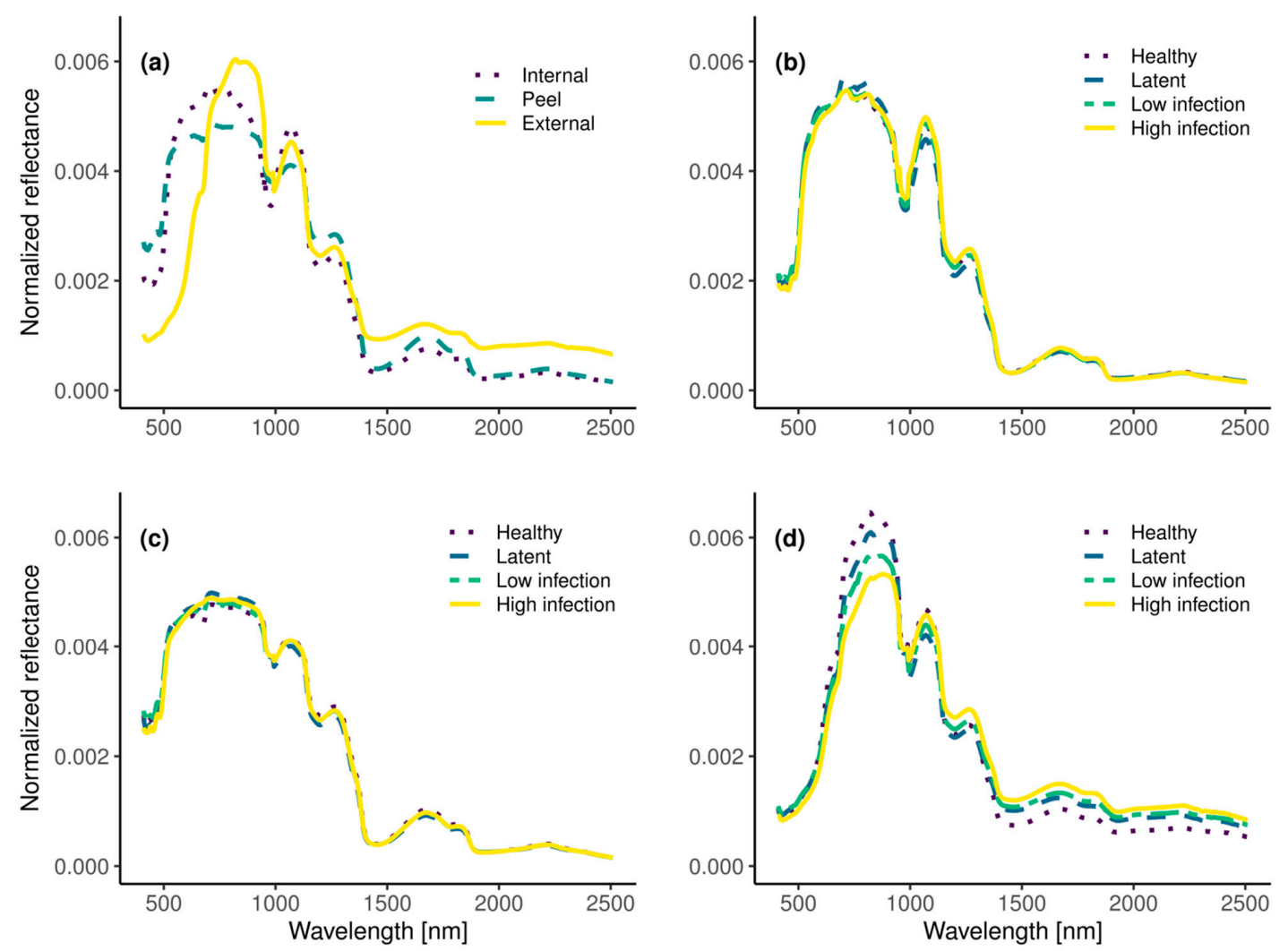

Figure 4. Mean spectral signatures of all groups. (a) Tuber preparation groups; (b) internal data from halved tubers; (c) data from peels; (d) epidermis data.
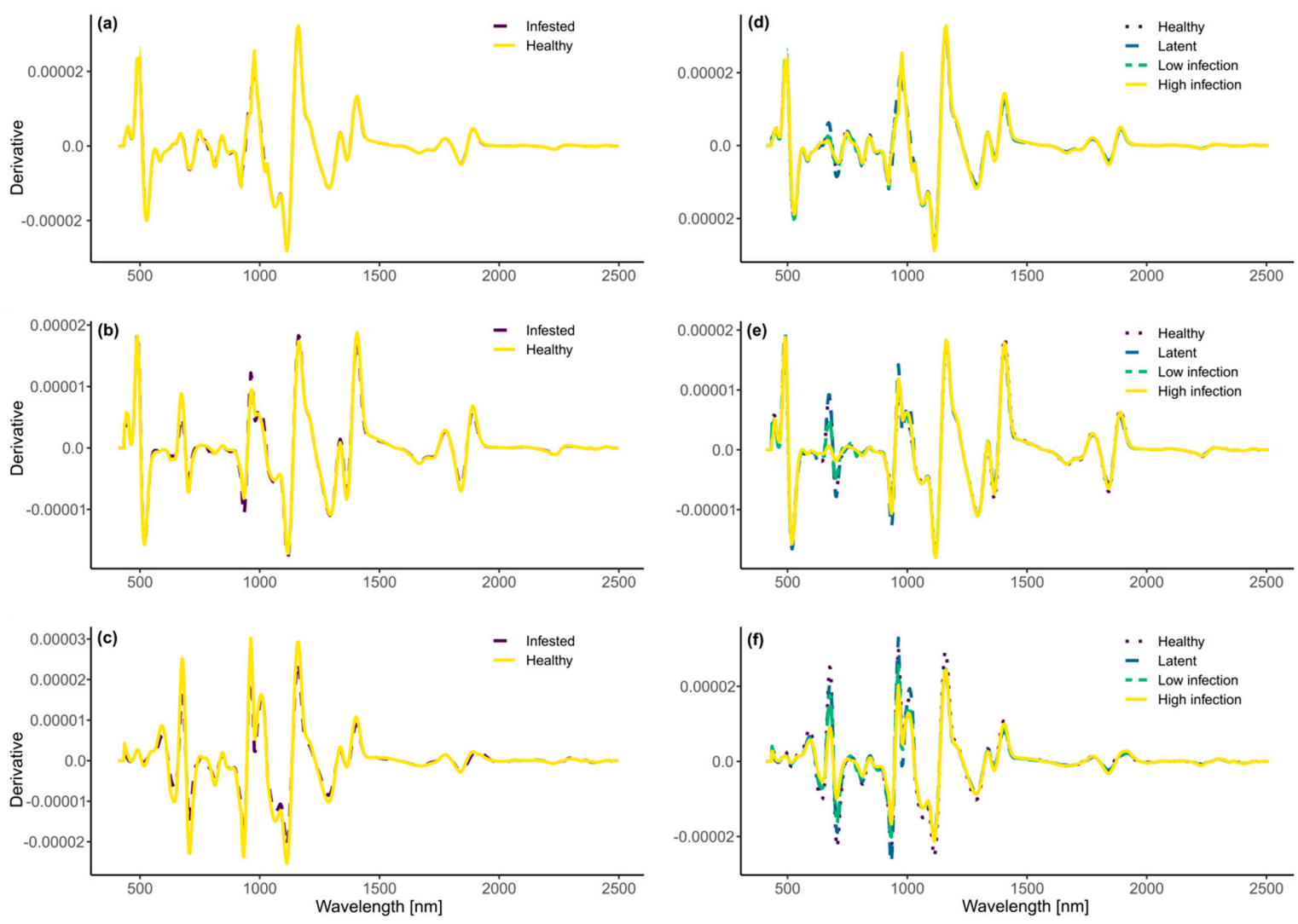

Figure 5. Savitzky-Golay derivative spectra. Left column: distinguishing between healthy and infested tubers; Right column: distinguishing between infestation severity groups. $(\mathbf{a}, \mathbf{d})$ internal data, $(\mathbf{b}, \mathbf{e})$ peel data, $(\mathbf{c}, \mathbf{f})$ external data. 


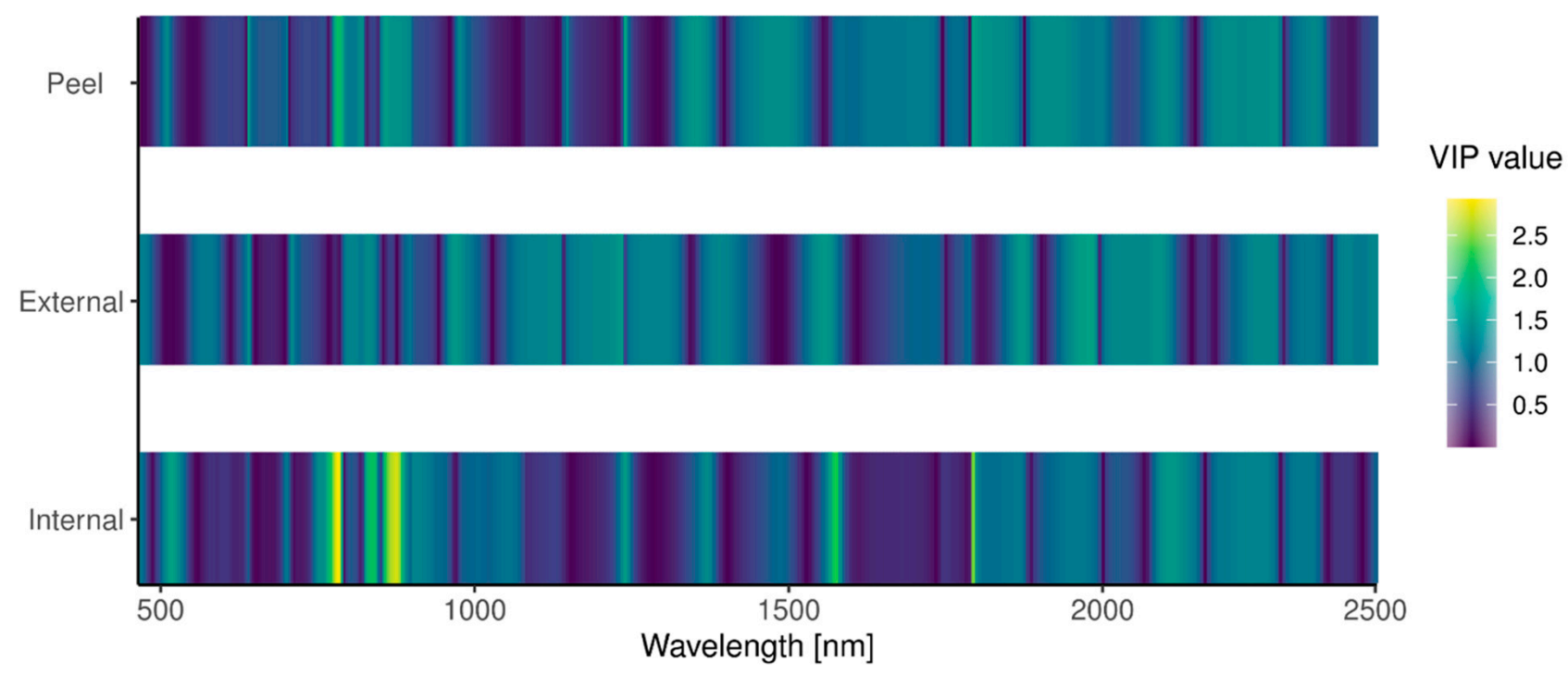

Figure 6. Variable importance in projection analysis results for identifying infested tubers and infestation severity. Wavelengths with a score above 1 were considered relevant.
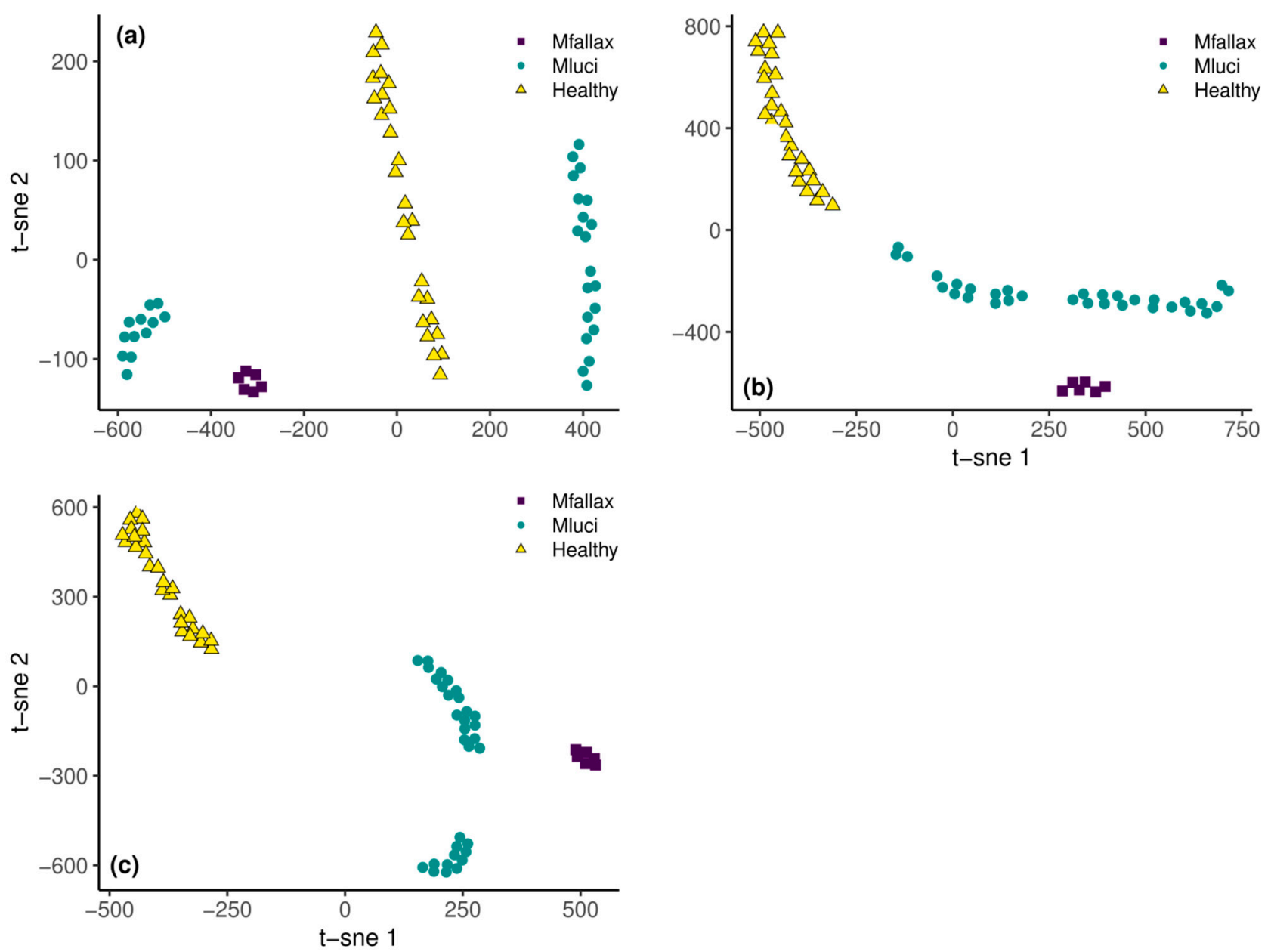

Figure 7. t-SNE scatter plots of Meloidogyne luci and M. fallax spectral derivative data: (a) internal data, (b) peels, (c) external data. 

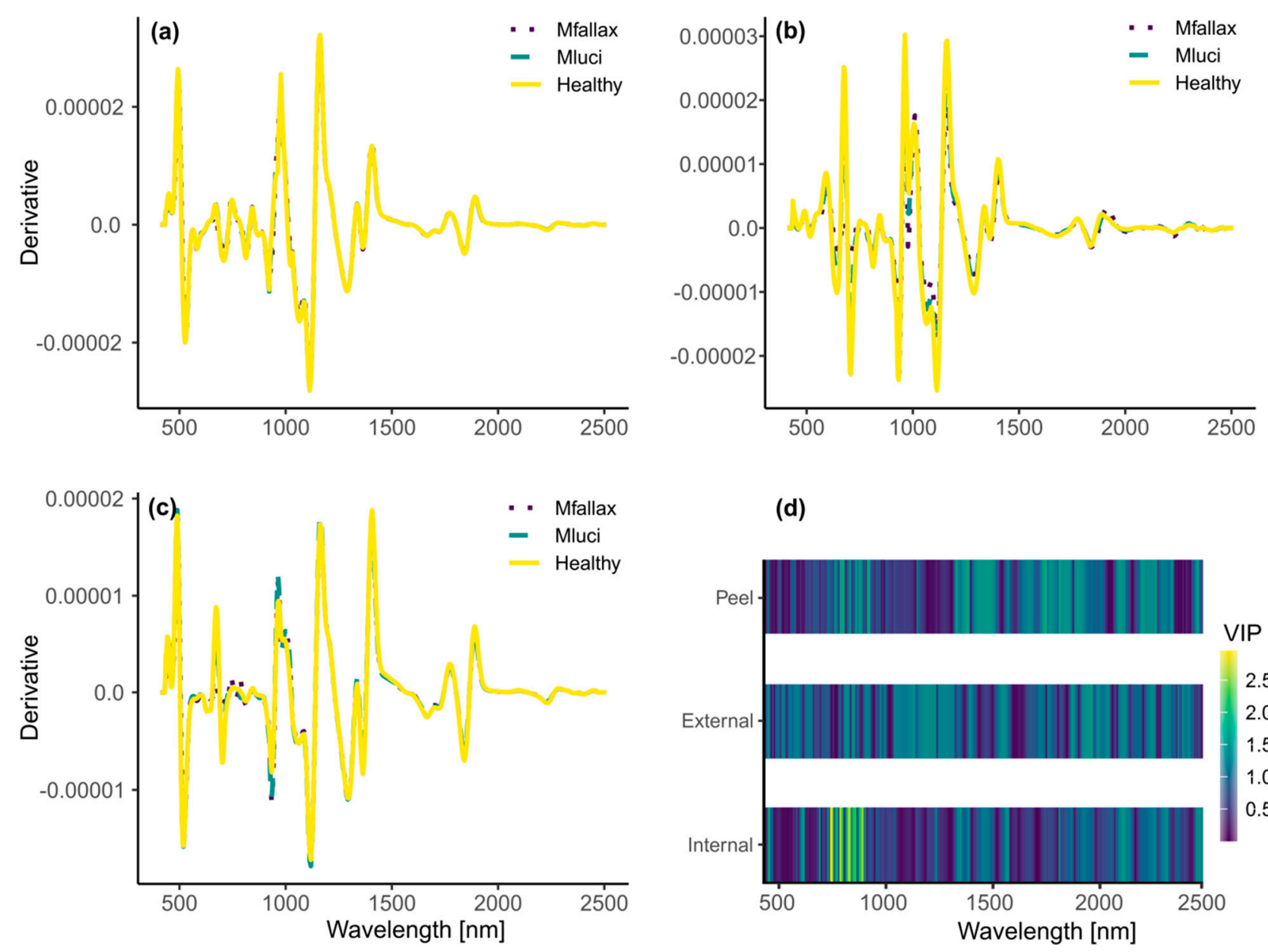

(d)

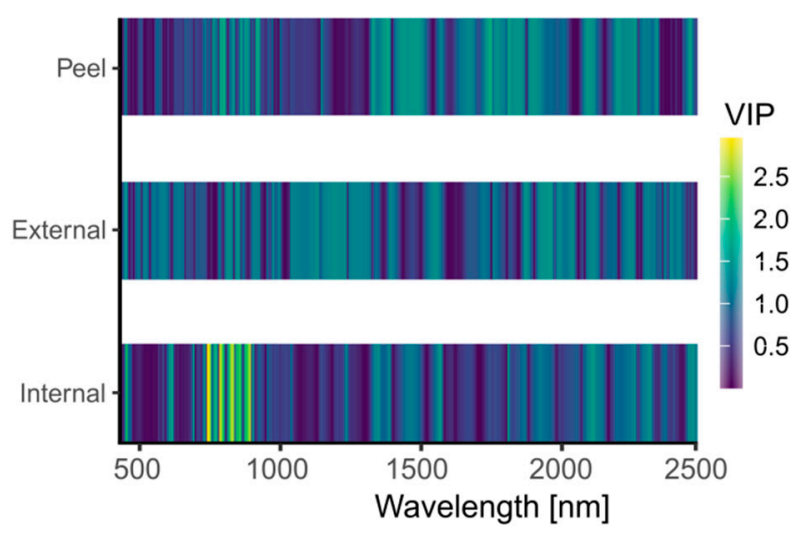

Figure 8. Spectral derivatives (a-c) and VIP results (d) of Meloidogyne luci and M. fallax data: (a) internal data, (b) peels, (c) external data, (d) VIP scores-wavelengths above 1 were considered as relevant for identifying nematode species.

Using real-time PCR with MEG primers, it was possible to detect $M$. luci both in infested potato tubers with visible symptoms and in tubers without visible symptoms, i.e., latent infestation (Figure 1, Table 1). Furthermore, it was possible to consistently detect M. luci in samples where only one peel of a symptomatic tuber was added to a sample of 100 peels in total, and when only three isolated females with egg mass attached were added to a sample of non-infested potatoes, showing the low detection limit and high analytical sensitivity of the protocol. On the other hand, a sample where only one female with egg mass attached was added to uninfested potato peels did not result in consistent detection. A specific fragment with a melting temperature (Tm) of $69.2 \pm 1.2{ }^{\circ} \mathrm{C}$ was amplified in the real-time PCR reactions. The length, i.e., $241 \mathrm{bp}$ of this specific amplicon was also confirmed by observation on a $1 \%$ agarose gel (data not shown). M. luci was not detected in any of the samples from the uninfested tubers, confirming that the decontamination of the mixer between samples was adequate (Table 1). Additional one month storage of tubers at $6{ }^{\circ} \mathrm{C}$ did not significantly influence the results (Table 1, samples of (i) 100 peels from the RKN treatment tubers without visible symptoms (latent infestation) and (ii) 99 peels from the uninfested (NC) treatment and one peel from the RKN treatment, one tuber with visible symptoms).

The parameters obtained for the standard curve were as follows: slope: -3.189 , intercept $(Y): 33.9, R^{2}: 0.939$, and efficiency $(E): 105.863 \%$, showing satisfactory amplification of the template DNA with the selected primers (Figure 9). Testing dilutions of M. luci DNA further confirmation the high analytical sensitivity of the real time PCR method, since a 
very low amount of template DNA could be detected. DNA was detected in the range from $66 \mathrm{fg}$ to $129.7 \mathrm{ng}$ of the template DNA in a real-time PCR reaction.

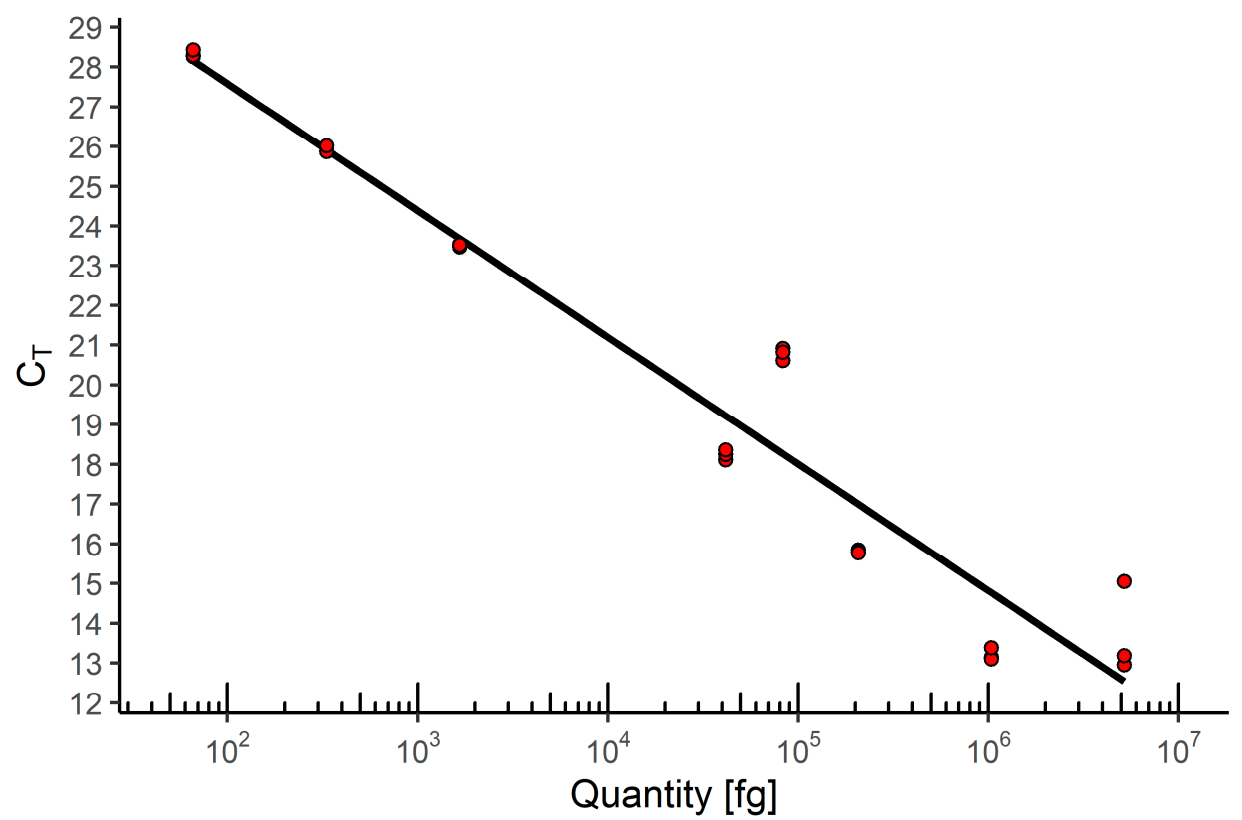

Figure 9. Standard curve for the detection of Meloidogyne luci with primers specific for the Meloidogyne ethiopica group (MEG), with the following parameters: slope: -3.189 , intercept (Y): $33.9, R^{2}: 0.939$, and efficiency (E): 105.863\%, showing satisfactory amplification of the template DNA with the selected primers. $\mathrm{C}^{\mathrm{T}}$ : threshold cycle, DNA quantity in femtograms (fg).

\section{Discussion}

Root-knot nematodes are considered the most aggressive, damaging, and economically important group of plant-parasitic nematodes and represent a significant limiting factor for potato production and tuber quality [50,51]. In addition to M. chitwoodi and M. fallax, which are regulated pests in the European Union, special attention should be paid to other RKN species that may have emerging importance for potato production. M. luci has been shown to have significant pest potential on the potato [2] and has already been isolated from potato fields in Europe [2,9]. M. luci develop similar symptoms to M. chitwoodi and M. fallax on potato tubers. In this study, it was shown that M. luci can develop latent infestations without visible external infestation symptoms on potato tubers, in addition to severe tuber infestations with visible infestation symptoms. Furthermore, most latently infested tubers remained latently infested even after 48 days of incubation when 2229 degree-days were reached (temperature sum was calculated as degrees above $5^{\circ} \mathrm{C}$ ) and did not develop external symptoms of infestation [52]. The incubation period, at $18{ }^{\circ} \mathrm{C}$ until a temperature sum of at least 2150 degree-days from the day of planting was reached, allowed $M$. chitwoodi and/or M. fallax to continue their life cycle and cause internal and/or external symptoms to become visible $[52,53]$.

Severe visible $M$. luci symptoms would reduce the market value of potatoes. Latent infestation can pose a high risk for uncontrolled spread of the pest, especially via seed potato. Testing of seed potatoes should be considered, as seed potatoes should be free of potato pests. We developed two detection methods for infestation of potato tubers with the root-knot nematode $M$. luci, one based on hyperspectral imaging and the other based on real-time PCR, both of which can detect both latent and severe infestations.

Hyperspectral imaging in the VNIR and SWIR spectral regions allows rapid, nondestructive detection of root-knot nematode-infested potato tubers. Preparation of the tubers did not significantly affect detection accuracy, suggesting that the response of the plants' immune system to nematode infestation in tubers is systemic. Although the majority of RKNs in potato tubers are located within the first $5.25 \mathrm{~mm}$ beneath the epidermis, i.e., 
within the vascular ring [54], the immune response is systemic. The visible symptoms of nematode infestation in potato tubers can vary widely between cultivars [55]. For example, brown lesions may develop in infested tubers in the cortex or the pith, and infested tubers may be without visible symptoms.

Identification of spectral ranges and patterns indicative of nematode infestation in the VNIR and SWIR regions could solve this problem. The peak-dip-peak pattern in the SWIR region is a good candidate as a fingerprint method for rapid assessment of nematode infestation in potato tubers. However, further studies are needed to ascertain whether this pattern also applies to other RKN species and potato varieties. Wavelengths between 800 and $2500 \mathrm{~nm}$ were identified as relevant for identifying infested tubers, with only a handful identified as relevant in the visible part of the spectrum. Several of these wavelengths are associated with proteins, hydrocarbons, cellulose, and lipids [56]. This suggests that nematode females in the vascular ring cause changes in the biochemical composition of tubers. The presence of wavelengths associated with water absorption is probably because nematodes interfere with water transport in plant tissues. On the other hand, several wavelengths in the visible to near-infrared portion of the spectrum were identified as relevant in distinguishing between nematode species. The visible part of the spectrum is associated with the color of the tuber interior, which is, in turn, an effect of the spectral properties of starch [56]. The prevalence of relevant wavelengths in the visible part of the spectrum to distinguish between nematode species suggests that nematode infestation alters the spectral properties of starch, and this alteration could be species-specific. However, further studies are required to fully test this hypothesis, as only a small sample of $M$. fallax infested tubers was used for these analyses.

In all cases, the water absorption band at approximately $970 \mathrm{~nm}$ was determined to be relevant. The peak-dip-peak pattern between 1776 and $1890 \mathrm{~nm}$ is associated with water absorption, but reflectance around $1770 \mathrm{~nm}$ is also associated with the methyl group in hydrocarbons. Aliphatic hydrocarbons are associated with several identified relevant wavelengths, for example 785, 812, 1146, 1238, 1352, and $1635 \mathrm{~nm}$ [56]. Different forms of hydrocarbons (e.g., aromatic at $1146 \mathrm{~nm}$, and methyl group at 1705 and $1765 \mathrm{~nm}$ ) as well as starch (at $1450 \mathrm{~nm}$ ) and glucose (at 2330-2336 nm, and the O-H stretch in glucose at $2276 \mathrm{~nm}$ ) were relevant for the detection of infestation inside the tubers. On the outside, however, proteins (e.g., the N-H stretch at 1559 and $1982 \mathrm{~nm}$ ), cellulose (at $2270 \mathrm{~nm}$ ), and lipids (at 2385) became more important, whereas hydrocarbons became less important [56].

Of the four wavelengths in the SWIR region relevant for discrimination between nematode species on internal and peel data, two (1091 and $1145 \mathrm{~nm}$ ) are associated with aromatic hydrocarbons and the C-N and N-H stretches in proteins, while $1346 \mathrm{~nm}$ is associated with aliphatic hydrocarbons. While aliphatic hydrocarbons predominated among hydrocarbons for identifying infested tubers, aromatic hydrocarbons (e.g., at 704 and $879 \mathrm{~nm}$ and the $\mathrm{C}-\mathrm{H}$ methyl group between 920 and $960 \mathrm{~nm}$ ) gain in importance when distinguishing nematode species. External data showed several additional relevant wavelengths in the SWIR, most of them associated with different hydrocarbons (e.g., aliphatic at $1384 \mathrm{~nm}$, and glucose at $2107 \mathrm{~nm}$ ) and cellulose (at $2281 \mathrm{~nm}$ ) [56]. In contrast to detection of infested tubers, only hydrocarbon-related wavelengths in the SWIR region were identified as relevant in discrimination of nematode species.

Root-knot nematode infestation in roots and tubers causes histological changes, such as cell hyperplasia and hypertrophy [55,57]. The extent of histological changes depends on cultivar resistance to RKN, with more susceptible cultivars showing greater changes. In addition, as a consequence of nematode attack, plant immune responses are activated by increasing the production and activity of chitinase, peroxidase, and catalase [57]. Chitinases hydrolise chitin, a protein that provides architectural reinforcement of nematode eggshells; peroxidases are associated with defense mechanisms against pathogens, and catalases catalyze the decomposition of hydrogen peroxide (it acts as an antimicrobial agent) to water and oxygen. Nematode infestation increases the activity of all three enzymes, and changes in absorbance at $470 \mathrm{~nm}$ have been associated with peroxidase and catalase activ- 
ity [57]. Furthermore, secondary metabolites such as glycoalkaloids possess antimicrobial and pesticidal properties. Their basic mechanism is to bind to cholesterol, disrupt cell membranes, and inhibit cholinesterases (they lyse choline-based esters that often function as neurotransmitters) [58,59].

The workflow of the real-time PCR method described here roughly follows the principle of the MeloTuber test [53], a real-time PCR based assay for direct detection of $M$. chitwoodi and M. fallax in potato tubers. The molecular approach using real-time PCR allowed reliable detection of $M$. luci nematode-infested tuber samples, with only one peel of a symptomatic tuber added to a sample of 99 peels from healthy control tubers. The low detection limit of the protocol was also demonstrated by the addition of only three isolated females to a sample of 100 peels from uninfested control potato tubers. To the best of the authors' knowledge, this is the first report of the detection of $M$. luci in infested potato tubers using a molecular approach. A disadvantage of other molecular tests is the required prior extraction of nematodes from the tuber, which is not suitable for high throughput screening. A control real-time PCR reaction for $18 \mathrm{~S}$ rRNA showed that one commercial kit for DNA isolation resulted in slightly lower $C_{T}$ values, but possibly other DNA isolation protocols could work comparatively well.

As both approaches were shown to be very efficient, they represent useful tools that could be implemented in phytosanitary surveillance programs. The disadvantage of morphometric, biochemical, and other molecular detection and identification methods is the need to extract the nematodes from the matrix (i.e., soil, plant tissue), which is not the case with the two methods developed here. For the M. luci monitoring program, the authors propose sampling similar to that used for the detection of M. chitwoodi and M. fallax, as described in Council Directive 2000/29/EC. One hundred tubers should be sampled and further analyzed as suggested in Supplementary Figure S3. Alternatively, to ensure even better detection of $M$. luci in seed potato lots, 200 tubers could be sampled randomly; all 200 tubers would be analyzed using the remote sensing approach and two subsamples of 100 tubers would be analyzed using real-time PCR.

Before implementation of the methods developed in diagnostic laboratories, further studies are needed to determine missing validation data (e.g., specificity of remote sensingbased detection, repeatability, reproducibility, robustness, and selectivity). The analytical specificity of the MEG primers used has been extensively evaluated previously [37]. With this real-time PCR approach, it is not possible to distinguish M. luci from M. ethiopica and $M$. inornata because the primers used are group-specific for three RKN species, namely M. luci, M. ethiopica, and M. inornata. The fact that the detection method also identifies M. ethiopica could be useful, since M. ethiopica is also a pest of the potato and is on the EPPO alert list. On the other hand, information on $M$. inornata is so scarce that it is not clear whether $M$. inornata can parasitise potatoes and has the potential to cause similar symptoms on potato tubers. As M. ethiopica, M. luci, and M. inornata are closely related [37], they could all have similar host ranges and symptoms on potato tubers, but this remains to be tested. In this study, the remote sensing approach was shown to distinguish M. luci from $M$. fallax infested tubers, but other RKN species were not tested. In addition, further testing is needed to determine if different potato cultivars affect the results of the detection methods developed, to establish the insensitivity of the tests to the potato cultivar. While it is unlikely that the potato cultivar will affect real-time PCR results, it is possible that the potato cultivar may affect hyperspectral signatures. Testing should also be performed immediately after the harvesting of potato tubers to determine whether or not storage of potato tubers and further development of the nematodes is necessary for successful detection.

A sample that yields a positive result using either of the two methods developed here should be further analyzed to determine the RKN species, preferably with determination of isoenzyme profiles (Supplementary Figure S3). A control real-time PCR reaction for 18S rRNA or another potato gene could be included to test for successful DNA isolation. 


\section{Conclusions}

In this study, it was shown that M. luci can develop latent infestation without visible infestation symptoms on the surface of potato tubers, in addition to severe tuber infestation with visible infestation symptoms. The development of sensitive and efficient methods for detecting the pest and conduction of national pest surveys are therefore critical.

The authors developed two approaches for the detection of M. luci infestation that are suitable for high-throughput detection of $M$. luci directly in potato tissue. Both are comparatively rapid and accurate methods for detecting potato tubers infested with rootknot nematodes. In addition, latent infestation can also be detected with a high level of accuracy.

Hyperspectral imaging analysis of derivative spectra, combined with the identification of relevant wavelengths using variable importance in projection analysis, revealed the presence of several spectral patterns that could be used as a rapid fingerprinting method for the detection of nematode infestation. However, further studies are needed to fully test this. The plant immune response and changes in N-containing bonds of proteins and secondary metabolites are mostly reflected in the SWIR region and are associated with infestation detection. In contrast to infestation detection, the VNIR range has gained importance for identification of the nematode species. This range is associated with pigment content and distribution, as well as tissue and structure. Further chemometric studies are required to fully understand the effects of different nematode species on potato tubers. Nevertheless, the detection of infested tubers is accurate enough to warrant further development of dedicated systems for on-the-fly assessment of tuber health.

Real-time PCR analysis detects the presence of $M$. luci with high sensitivity, but the method is not species-specific. It is not possible to distinguish M. luci from M. ethiopica and $M$. inornata because the primers used are group-specific for three RKN species, namely $M$. luci, M. ethiopica, and M. inornata.

Supplementary Materials: The following are available online at https:/ / www.mdpi.com/article/10 $.3390 / \mathrm{rs} 13101996 / \mathrm{s} 1$, Figure S1: The homogenized samples were poured from the mixing bowl into a $250 \mathrm{~mL}$ single use plastic container and allowed to settle for three minutes. Then, $1 \mathrm{~mL}$ of the middle layer of the suspension (i.e., clear liquid layer designated with an arrow) was transferred to a $1.5 \mathrm{~mL}$ microcentrifuge and allowed to settle for $10 \mathrm{~min}$. Figure S2: Typical thickening of the roots called gall caused by Meloidogyne luci infestation observed on Solanum tuberosum roots indicated by an arrow. M. luci can infest roots as well of tubers. Figure S3: Proposed schematic flow of M. luci detection and identification in seed potatoes. Real-time PCR MEG-Real-time PCR with primers specific for Meloidogyne ethiopica group, i.e., M. luci, M. ethiopica and M. inornata. Protocols for DNA isolation with the KingFisher mL magnetic particle processor (Thermo Electron, Waltham, MA, USA): Protocol S1: 'LGC barb 2020.kf2' for DNA isolation used with the Sbeadex maxi plant kit (LGC Genomics, Berlin, Germany) and Protocol S2: 'promega food 65C.kf2' used with the Wizard Magnetic DNA Purification System for Food kit (Promega, Madison, WI, USA).

Author Contributions: Conceptualisation, S.Š., U.Ž. and B.G.S.; methodology, U.Ž. and B.G.S.; formal analysis, U.Ž., J.L., S.Š. and B.G.S.; writing—original draft preparation, S.Š., U.Ž. and B.G.S.; writing-review and editing, N.S., M.K., J.L., S.Š., U.Ž. and B.G.S.; funding acquisition, S.Š., U.Ž., B.G.S., M.K., U.Ž. and B.G.S. contributed equally to this work as first authors. All authors have read and agreed to the published version of the manuscript.

Funding: The research was supported by funds from the European Food Safety Authority (grant GP/EFSA/ALPHA/2018/02), and the Slovenian Research Agency (ARRS) (MR 38128, MR 54720, P40072). Some of the research was conducted using equipment financed by EU-FP7 project CropSustaIn, grant agreement FP7-REGPOT-CT2012-316205. The position and opinions presented in this paper are those of the authors alone and do not necessarily represent the views of EFSA.

Institutional Review Board Statement: Not applicable.

Informed Consent Statement: Not applicable. 
Data Availability Statement: The real-time PCR data presented in this study are available in Table 1. Raw data for real-time PCR and remote sensing presented in this study are available on request from the corresponding author.

Conflicts of Interest: The authors declare no conflict of interest. The funders had no role in the design of the study, the collection, analysis or interpretation of data, the writing of the manuscript, or the decision to publish the results.

\section{References}

1. EPPO Global Database: Meloidogyne chitwoodi. EPPO Datasheets on Pests Recommended for Regulation. Available online: https://gd.eppo.int (accessed on 9 April 2021).

2. Maleita, C.; Esteves, I.; Cardoso, J.M.S.; Cunha, M.J.; Carneiro, R.M.D.G.; Abrantes, I. Meloidogyne luci, a new root-knot nematode parasitizing potato in Portugal. Plant Pathol. 2018, 67, 366-376. [CrossRef]

3. Carneiro, R.M.D.G.; Correa, V.R.; Almeida, M.R.A.; Gomes, A.C.M.M.; Deimi, A.M.; Castagnone-Sereno, P.; Karssen, G. Meloidogyne luci n. sp. (Nematoda: Meloidogynidae), a root-knot nematode parasitising different crops in Brazil, Chile and Iran. Nematology 2014, 16, 289-301. [CrossRef]

4. Gerič Stare, B.; Strajnar, P.; Susič, N.; Urek, G.; Širca, S. Reported populations of Meloidogyne ethiopica in Europe identified as Meloidogyne luci. Plant Dis. 2017, 101, 1627-1632. [CrossRef] [PubMed]

5. Širca, S.; Urek, G.; Karssen, G. First report of the root-knot nematode Meloidogyne ethiopica on tomato in Slovenia. Plant Dis. 2004, 88, 680. [CrossRef]

6. Gerič, S.B.; Strajnar, P.; Širca, S.; Susič, N.; Urek, G. Record of a new location for tropical root knot nematode Meloidogyne luci in Slovenia. Bull. OEPP/EPPO Bull. 2018, 48, 135-137. [CrossRef]

7. Maleita, C.M.; José, S.M.; Egas, C.; Curtis, R.H.C.; Abrantes, I.M.O. Biometrical, biochemical, and molecular diagnosis of Portuguese Meloidogyne hispanica isolates. Plant Dis. 2012, 96, 865-874. [CrossRef]

8. Conceição, I.L.; Tzortzakakis, E.A.; Gomes, P.; Abrantes, I.; Cunha, M.J. Detection of the root-knot nematode Meloidogyne ethiopica in Greece. Eur. J. Plant Pathol. 2012, 134, 451-457. [CrossRef]

9. Santos, D.; Correia, A.; Abrantes, I.; Maleita, C. New hosts and records in Portugal for the root-knot nematode Meloidogyne luci. J. Nematol. 2019, 51, 1-4. [CrossRef]

10. Rusinque, L.; Nóbrega, F.; Cordeiro, L.; Serra, C.; Inácio, M.L. First detection of Meloidogyne luci (Nematoda: Meloidogynidae) parasitizing potato in the Azores, Portugal. Plants 2021, 10, 99. [CrossRef]

11. Strajnar, P.; Širca, S.; Knapič, M.; Urek, G. Effect of Slovenian climatic conditions on the development and survival of the root-knot nematode Meloidogyne Ethiopica. Eur. J. Plant Pathol. 2011, 129, 81-88. [CrossRef]

12. EPPO Alert List: Addition of Meloidogyne luci together with M. ethiopica; EPPO Reporting Service No. 11-2017, Num. Article: 2017/218. Available online: https:/ /gd.eppo.int/reporting/article-6186 (accessed on 2 March 2021).

13. Cunha, G.T.; Visôtto, L.I.; Lopes, E.A.; Oliveira, C.M.G.; God, P.I.V.G. Diagnostic methods for identification of root-knot nematodes species from Brazil. Crop Prot. 2018, 48, 2. [CrossRef]

14. Elmasry, G.; Kamruzzaman, M.; Sun, D.W.; Allen, P. Principles and applications of hyperspectral imaging in quality evaluation of agro-food products: A review. Crit. Rev. Food Sci. Nutr. 2012, 52, 999-1023. [CrossRef]

15. Brugger, A.; Behmann, J.; Paulus, S.; Luigs, H.G.; Kuska, M.T.; Schramowski, P.; Kersting, K.; Steiner, U.; Mahlein, A.K. Extending hyperspectral imaging for plant phenotyping to the UV-range. Remote Sens. 2019, 11, 1401. [CrossRef]

16. Voigt, C.A. Callose-mediated resistance to pathogenic intruders in plant defence-related papillae. Front. Plant Sci. 2014, 5, 168. [CrossRef] [PubMed]

17. Susič, N.; Žibrat, U.; Širca, S.; Strajnar, P.; Razinger, J.; Knapič, M.; Vončina, A.; Urek, G.; Gerič Stare, B. Discrimination between abiotic and biotic drought stress in tomatoes using hyperspectral imaging. Sens. Actuators B Chem. 2018, 273, 842-852. [CrossRef]

18. Susič, N.; Žibrat, U.; Sinkovič, L.; Vončina, A.; Razinger, J.; Knapič, M.; Sedlar, A.; Širca, S.; Gerič, S.B. From genome to fieldObservation of the multimodal nematicidal and plant growth-promoting effects of Bacillus firmus I-1582 on tomatoes using hyperspectral remote sensing. Plants 2020, 9, 592. [CrossRef] [PubMed]

19. Jensen, J.R. Remote Sensing of the Environment: An Earth Resource Perspective, 2nd ed.; Pearson Prentice Hall: Upper Saddle River, NJ, USA, 2007; p. 592.

20. Sankaran, S.; Mishra, A.; Ehsani, R.; Davis, C. A review of advanced techniques for detecting plant diseases. Comput. Electron. Agric. 2010, 72, 1-13. [CrossRef]

21. Mahlein, A.K.; Oerke, E.C.; Steiner, U.; Dehne, H.W. Recent advances in sensing plant diseases for precision crop protection. Eur. J. Plant Pathol. 2012, 133, 197-209. [CrossRef]

22. Ji, Y.; Sun, L.; Li, Y.; Li, J.; Liu, S.; Xie, X.X.Y. Non-destructive classification of defective potatoes based on hyperspectral imaging and support vector machine. Infrared Phys. Technol. 2019, 99, 71-79. [CrossRef]

23. Lopez, M.A.; Keresztes, J.C.; Goodarzi, M.; Arazuri, A.; Jaren, C.; Saeys, W. Non-destructive detection of blackspot in potatoes by Vis-NIR and SWIR hyperspectralimaging. Food Control 2016, 70, 229-241. [CrossRef]

24. Amjad, W.; Crichton, S.O.J.; Munir, A.; Hensel, O.; Sturm, B. Hyperspectral imaging for the determination of potato slice moisture content and chromaticity during the convective hot air drying process. Biosyst. Eng. 2018, 166, 170-182. [CrossRef] 
25. Ji, Y.; Sun, L.; Li, Y.; Ye, D. Detection of bruised potatoes using hyperspectral imaging technique based on discrete wavelet transform. Infrared Phys. Technol. 2019, 103, 103054. [CrossRef]

26. Su, W.H.; Bakalis, S.; Sun, D.W. Fourier transform mid-infrared-attenuated total reflectance (FTMIR-ATR) microspectroscopy for determining textural property ofmicrowave baked tuber. J. Food Eng. 2018, 218, 1-13. [CrossRef]

27. Su, W.H.; Sun, D.W. Chemical imaging for measuring the time series variations of tuber dry matter and starch concentration. Comput. Electron. Agric. 2017, 140, 361-373. [CrossRef]

28. Ayvaz, H.; Santos, A.M.; Moyseenko, J.; Kleinhenz, M.; Rodriguez-Saona, L.E. Application of a portable infrared instrument for simultaneous analysis of sugars, asparagine and glutamine levels in raw potato tubers. Plant Foods Hum. Nutr. 2015, 70, 215-220. [CrossRef] [PubMed]

29. Dacal-Nieto, A.; Formella, A.; Carrión, P.; Vazquez-Fernandez, E.; Fernández-Delgado, M. Non-Destructive Detection of Hollow Heart in Potatoes Using Hyperspectral Imaging. In Proceedings of the Computer Analysis of Images and Patterns; Real, P., Diaz-Pernil, D., Molina-Abril, H., Berciano, A., Kropatsch, W., Eds.; Springer: Berlin/Heidelberg, Germany, 2011; pp. 180-187. [CrossRef]

30. Huang, T.; Li, X.Y.; Xu, M.L.; Jin, R.; Ku, J.; Xu, S.M. Non-destructive detection research for hollow heart of potato based on semi-transmission hyperspectral imaging and SVM. Spectrosc. Spect. Anal. 2015, 35, 198-202. [CrossRef]

31. Riza, D.F.A.; Suzuki, T.; Ogawa, Y.; Kondo, N. Diffuse reflectance characteristic of potato surface for external defects discrimination. Postharvest Biol. Technol. 2017, 133, 12-19. [CrossRef]

32. Santos, D.; Martins da Silva, P.; Abrantes, I.; Maleita, C. Tomato Mi-1.2 gene confers resistance to Meloidogyne luci and M. ethiopica. Eur. J. Plant Pathol. 2020, 156, 571-580. [CrossRef]

33. Žibrat, U.; Širca, S.; Susič, N.; Knapič, M.; Gerič Stare, B.; Urek, G. Noninvasive detection of plant parasitic nematodes using hyperspectral and other remote sensing systems. In Hyperspectral Remote Sensing: Theory and Applications; Earth Observation, Series; Pandey, P.C., Srivastava, P.K., Balzter, H., Bhattacharya, B., Petropoulos, G.P., Eds.; Elsevier: Amsterdam, The Netherlands, 2020; pp. 357-375. [CrossRef]

34. Janssen, T.; Karssen, G.; Verhaeven, M.; Coyne, D.; Bert, W. Mitochondrial coding genome analysis of tropical root-knot nematodes (Meloidogyne) supports haplotype based diagnostics and reveals evidence of recent reticulate evolution. Sci. Rep. 2016, 6, 1-13. [CrossRef]

35. Correa, V.R.; Mattos, V.S.; Almeida, M.R.A.; Santos, M.F.A.; Tigano, M.S.; Castagnone-Sereno, P.; Carneiro, R.M.D.G. Genetic diversity of the root-knot nematode Meloidogyne ethiopica and development of a species-specific SCAR marker for its diagnosis. Plant Pathol. 2014, 63, 476-483. [CrossRef]

36. Santos, M.F.A.; Mattos, V.S.; Monteiro, J.M.S.; Almeida, M.R.A.; Jorge, A.S.; Cares, J.E.; Castagnone-Sereno, P.; Coyne, D.; Carneiro, R.M.D.G. Diversity of Meloidogyne spp. from peri-urban areas of sub-Saharan Africa and their genetic similarity with populations from the Latin America. Physiol. Mol. Plant Pathol. 2019, 105, 110-118. [CrossRef]

37. Gerič Stare, B.; Aydınlı, G.; Devran, Z.; Mennan, S.; Strajnar, P.; Urek, G.; Širca, S. Recognition of species belonging to Meloidogyne ethiopica group and development of a diagnostic method for its detection. Eur. J. Plant Pathol. 2019, 154, 621-633. [CrossRef]

38. Hussey, R.S.; Barker, K.R. Comparison of methods of collecting inocula for Meloidogyne spp., including a new technique. Plant Dis. Rep. 1973, 57, 1025-1028.

39. Piqueras, S.; Burger, J.; Tauler, R.; Juan, A. Relevant aspects of quantification and sample heterogeneity in hyperspectral image resolution. Chemometr. Intell. Lab. Syst. 2012, 117, 169-182. [CrossRef]

40. Žibrat, U.; Susič, N.; Knapič, M.; Širca, S.; Strajnar, P.; Razinger, J.; Vončina, A.; Urek, G.; Gerič Stare, B. Pipeline for imaging, extraction, pre-processing, and processing of time-series hyperspectral data for discriminating drought stress origin in tomatoes. MethodsX 2019, 6, 300-408. [CrossRef] [PubMed]

41. Chang, C.I. An information-theoretic approach to spectral variability, similarity, and discrimination for hyperspectral image analysis. IEEE Trans. Inf. Theory 2000, 46, 1927-1932. [CrossRef]

42. Maaten, L.; Hinton, G.E. Visualizing data using t-SNE. J. Mach. Learn. Res. 2008, 9, 2579-2605.

43. Ballabio, D.; Consonni, V. Classification tools in chemistry. Part 1: Linear models. Anal. Methods 2013, 5, 3790-3798. [CrossRef]

44. Chong, I.G.; Jun, C.H. Performance of some variable selection methods when multicollinearity is present. Chemom. Intell. Lab. Syst. 2005, 78, 103-112. [CrossRef]

45. R Core Team. R: A Language and Environment for Statistical Computing; R Foundation for Statistical Computing: Vienna, Austria, 2015.

46. Rohart, F.; Gautier, B.; Singh, A.; Le Cao, K.A. mixOmics: An R package for 'omics feature selection and multiple data integration. PLoS Comput. Biol. 2017, 13. [CrossRef]

47. Kuhn, M. Caret: Classification and Regression Training; (Version 6.0.86); R. Astrophysics Source Code Library. CRAN: 2015. Available online: https: / CRAN.R-project.org/package=caret (accessed on 30 March 2021).

48. Donaldson, J. tsne: T-Distributed Stochastic Neighbor Embedding for R (t-SNE); (Version 0.1.3); R. CRAN: 2016. Available online: https: / /CRAN.R-project.org/package=tsne (accessed on 30 March 2021).

49. Susič, N.; Koutsovoulos, G.D.; Riccio, C.; Danchin, E.G.J.; Blaxter, M.L.; Lunt, D.H.; Strajnar, P.; Širca, S.; Urek, G.; Stare, B.G. Genome sequence of the root-knot nematode Meloidogyne luci. J. Nematol. 2020, 52, 1-5. [CrossRef]

50. Jones, J.T.; Haegeman, A.; Danchin, E.G.J.; Gaur, H.S.; Helder, J.; Jones, M.G.K.; Kikuchi, T.; Manzanilla-López, R.; Palomares-Rius, J.E.; Wesemael, W.M.L.; et al. Top 10 plant-parasitic nematodes in molecular plant pathology. Mol. Plant Pathol. 2013, 14, 946-961. [CrossRef] 
51. Lima, F.S.O.; Mattos, S.V.; Silva, S.E.; Carvalho, M.A.S.; Teixeira, R.A.; Silva, J.C.; Correa, V.R. Nematodes Affecting Potato and Sustainable Practices for Their Management. In Potato_From Incas to All over the World, 1st ed.; Yildiz, M., Ed.; IntechOpen: London, UK, 2018; Volume 1, pp. 107-121.

52. EPPO. PM 3/69 (2) Meloidogyne chitwoodi and M. fallax sampling potato tubers for detection. Bull. OEPP/EPPO Bull. 2019, 49, 486-487. [CrossRef]

53. De Haan, E.G.; Dekker, C.C.E.M.; Tameling, W.I.L.; den Nijs, L.J.M.F.; van den Bovenkamp, G.W.; Kooman-Gersmann, M. The MeloTuber test: A real-time TaqMan ${ }^{\circledR}$ PCR-based assay to detect the root-knot nematodes Meloidogyne chitwoodi and M. fallax directly in potato tubers. Bull. OEPP/EPPO Bull. 2014, 44, 166-175. [CrossRef]

54. Viaene, N.; Mahieu, T.; Peña, E. Distribution of Meloidogyne chitwoodi in potato tubers and comparison of extraction methods. Nematology 2007, 9, 143-150. [CrossRef]

55. Finley, A.M. Histopathology of Meloidogyne chitwoodi (Golden et al.) on Russet Burbank potato. J. Nematol. 1981, $13,483$.

56. Workman, J., Jr.; Weyer, L. Practical Guide and Spectral Atlas for Interpretative Near-Infrared Spectroscopy, 2nd ed.; CRC Press: New York, NY, USA, 2012; pp. 231-249. ISBN 9781439875254.

57. Abd-Elgawad, M.M.M.; Kerlan, M.-C.; Molinari, S.; Abd-El-Kareem, F.; Kabeil, S.S.A.; Mohamad, M.M.; El-Nagdi, W.A. Histopathological changes and enzymatic activities induced by Meloidogyne incognita on resistant and susceptible potato. J. Plant Pathol. 2012, 1, 62-72. [CrossRef]

58. Colović, M.B.; Krstić, D.Z.; Lazarević-Pašti, T.D.; Bondžić, A.M.; Vasić, V.M. Acetylcholinesterase inhibitors: Pharmacology and toxicology. Curr. Neuropharmacol. 2013, 11, 315-335. [CrossRef]

59. Mandel, F. Tomato glycoalkaloids: Role in the plant and in the diet. J. Agric. Food Chem. 2002, 50, 5751-5780. [CrossRef] 